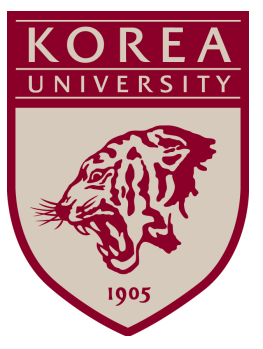

Discussion Paper Series

No. 1802

January 2021

\title{
Entry Deterrence and Free Riding in License Auctions: Incumbent Heterogeneity and Monotonicity
}

\author{
Biung-Ghi Ju Seung Han Yoo
}

The Institute of Economic Research - Korea University

Anam-dong, Sungbuk-ku, Seoul, 136-701, South Korea, Tel: (82-2) 3290-1632, Fax: (82-2) 928-4948

Copyright (C) 2021 IER. 


\title{
Entry Deterrence and Free Riding in License Auctions: Incumbent Heterogeneity and Monotonicity*
}

\author{
Biung-Ghi Ju $\quad$ Seung Han Yoo ${ }^{\ddagger}$
}

January 2021

\begin{abstract}
We examine free riding for entry deterrence in license auctions with heterogeneous incumbents. We establish the monotonicity of randomized preemptive bidding equilibria: an incumbent with a higher entry-loss rate has greater free-riding incentive, choosing a lower deterring probability. We then identify conditions for the existence of a series of fully or partially participating equilibria such that two or more incumbents with bounded heterogeneity in their entry-loss rates participate in randomized preemptive bidding. As an application, we examine a simple case of a bipartite group of participating incumbents consisting of one "leader" and many "followers". We show that the policy of limiting the leader's participation (set-asides for entrants, limiting participation of incumbents with excessive market shares, etc.) may or may not increase entry probability.
\end{abstract}

Keywords: entry deterrence, free-rider problem, asymmetric auctions

JEL Classification Numbers: D44, D47, L13

\footnotetext{
*This paper supersedes our earlier working paper, "License Auctions and Market Structure: Equilibrium Characterization." We would like to thank Jay P. Choi, Tapan Mitra and Kiho Yoon for their helpful comments. Of course, all remaining errors are ours.

${ }^{\dagger}$ Department of Economics, Seoul National University, 1 Gwanak-ro, Gwanak-gu, Seoul, Republic of Korea, 08826 (e-mail: bgju@snu.ac.kr).

${ }^{\ddagger}$ Department of Economics, Korea University, 145 Anam-ro, Seongbuk-gu, Seoul, Republic of Korea, 02841 (e-mail: shyoo@korea.ac.kr).
} 


\section{Introduction}

Entry deterrence is one of the major issues of competition policy and law. Its negative social consequences are rather apparent and well established by Gilbert and Newbery (1982) in an auction with a monopolistic incumbent and an entrant, and quite earlier by Arrow (1962) in patent licensing. However, its effectiveness and policy implications are somewhat subtle in industries with multiple incumbent competitors due to the free-rider problem among them. When incumbents cannot collude, entry deterring investment by an incumbent becomes a "public good" for the other incumbents, and this public good aspect may lead incumbents to make suboptimal investment decisions. Nevertheless, Bernheim (1984) and Gilbert and Vives (1986) find that the free-rider problem is not a significant factor in models of entry deterring investment decisions. Yet, adding to their models uncertainty in the effectiveness of preemptive investment, Waldman (1987) shows that the free-rider problem can be significant and incumbents may underinvest in entry deterrence. While uncertainty is exogeneous in Waldman (1987), in license auctions with externalities (concerning downstream competition), uncertainty arises endogeneously with incumbents' randomized attempts to bid preemptively and a new firm may have a chance to win a license, as shown by Hoppe, Jehiel and Moldovanu (2006; hereinafter HJM).

Despite the vast interest and extensive study on entry deterrence, little attention has been paid to how heterogeneity of incumbents shapes differential incentives of entry deterrence and affects incumbents' preemptive decisions. Our main objective is to investigate the free-rider problem in entry deterrence among heterogeneous incumbents. Incumbent heterogeneity is quite common in many industries. For example, the mobile telephony industry worldwide tends to have a few dominant or leading companies and followers. ${ }^{1}$ Understanding the effects of incumbent heterogeneity in the context of entry deterrence helps us provide more robust policy implications. We consider this issue in a single license auction with downstream competition. It is a simple case of the multi-license auction studied by HJM, who consider homogeneous incumbents.

We establish the monotonicity of preemptive bidding participation with regard to the entry-loss rate (the rate of loss an incumbent faces when an entry takes place relative to her intrinsic value of the license). In all equilibria with two or more incumbents participating in preemptive bidding, the higher the entry-loss rate, the lower the probability of preemptive bidding. An incumbent with a higher entry-loss rate has greater incentive of entry-deterrence. Then, at first glance, our monotonicity result seems counterintuitive since it would make sense for an incumbent with a higher entry-loss rate to have a greater incentive of preemption and to bid more aggressively. However, in order to make two or more incumbents participate in preemptive bidding, all participating incumbents need to engage in strictly randomized preemption, which requires giving them free-riding incentive. When an incumbent has a higher entry-loss rate, to give her free-riding incentive, the other incumbents need to preemptively bid with greater probability. This results in an inverse relation between entry-loss rates and probabilities of preemptive bidding. A similar counterintuitive comparative statics for the case of strictly mixed strategies was formalized by Crawford and

\footnotetext{
${ }^{1}$ See the Federal Communications Commission twentieth report (FCC 17-126) for asymmetry in the U.S. market share among mobile companies during 2013-2016: 35\% for Verizon Wireless, $32.4 \%$ for AT \& T, 17.1\% for T-mobile, $14.3 \%$ for Sprint, and 1.2\% for U.S. Cellular; and the Ofcom Communications Market Report 2016 for asymmetry in the U.K. market share in 2015: $29 \%$ for EE, $27 \%$ for O2, $19 \%$ for Vodafone, $15 \%$ for others, and $11 \%$ for Three.
} 
Smallwood (1984) in two-player zero-sum games. ${ }^{2}$ The comparative statics is experimentally tested and endorsed by Amaldoss and Sanjay (2002).

Based on the monotonicity result, we show that if entry-loss rates exhibit bounded heterogeneity, a fully participating randomized preemption (FPRP) equilibrium exists and is unique. In a FPRP equilibrium, none of the participating incumbents is perfectly free-riding and none of them takes the full responsibility for entry deterrence, either. Next, we examine a more interesting case: equilibria where two or more (not necessarily all) incumbents participate in preemptive bidding, called a partially participating randomized preemption (PPRP) equilibrium. We show that a PPRP equilibrium exists if entry-loss rates of the participating incumbents exhibit bounded heterogeneity and their maximum rate is greater than the rates of non-participating incumbents. Thus, no nonparticipating incumbent can have an entry-loss rate greater than that of any of the participating incumbents. Hence, our results provide two contrasting monotonicity properties, that is, between participants and non-participants, entry-loss rates are "greater" for the former than the latter; yet among participants, entry-loss rates are greater for incumbents whose probabilities of preemptive bidding are lower.

We next examine the case where those incumbents participating in randomized preemptive bidding constitute a bipartite group of a single leader and followers, which arises in both Cournot competition and Stackelberg competition. We show that existence of these "leader-follower" PPRP equilibria may hold without the bounded-heterogeneity condition. In industries with a leader and followers, a reasonable policy option promoting the competitiveness of the downstream market is to exclude the leader in the auction design. This policy may or may not increase the chance of a new entry; the ramification of the two possibilities is identified through certain conditions on equilibrium strategies.

For government procurement and sales, many countries adopt set-asides or policies to exclude some incumbents with excessive market power, and this area is of increasing interest in research and policy (for example, Athey, Coey, and Levin (2013) and Jehiel and Lamy (2015)). These policies are used to promote competitiveness in the down-stream market by limiting the market power of leading incumbents or by encouraging a new entry (see Ayres and Cramton (1996) for broad discussions about the policy). When incumbents are homogeneous, HJM show that as the number of preemptive incumbents increases, the probability of a new entry rather increases. We obtain a similar result, as a corollary to our results, by comparing PPRP equilibria with different numbers of participating incumbents with an identical entry-loss rate; so limiting participation of some incumbents is not desirable from the perspective of competitiveness. ${ }^{3}$ However, in leaderfollower PPRP equilibria of this paper, it is possible to increase the chance of entry by excluding the leader in the auction. Thus, we identify conditions under which the affirmative action can be effective.

This paper is also related to two strands in the auction literature: asymmetric auctions (Lebrun (1999), Maskin and Riley (2000) and Kirkegaard (2012) among others) and auctions with externalities (see Jehiel and Moldovanu $(2000,2001)$ ). We study asymmetric auctions with externalities

\footnotetext{
${ }^{2}$ In spite of controversy, the mixed strategy equilibrium concept has become widely accepted for a large number of applications. Cheng and Zhu (1995) show that such anomalies can be traced back to von Neumann and Morgenstern's expected utility, but, still, it is the most common form of decision making under uncertainty.

${ }^{3}$ The same insight was provided also by Sharkey and Sibley (1993) with a number of firms in a Bertrand model.
} 
under complete information, but it is not difficult to see how incomplete information with different valuation distributions can render analysis combining asymmetric auctions and externalities complex. ${ }^{4}$ We suggest a tractable model under complete information that can embark on studying the role of asymmetric incumbents in entry deterrence. This model can also be extended to consider entry deterrence and litigation with asymmetric firms to generalize the homogeneity assumption among firms; for instance, see a recent study by Choi and Gerlach (2018).

The model is introduced in Section 2, and preliminary definitions and facts are provided in Section 3. Section 4 and 5 present the general results. Section 6 deals with a special case involving a leader and many followers. We conclude with a few remarks in Section 7. Most proofs are provided in the appendix.

\section{Model}

We consider an industry with multiple heterogeneous incumbents and potential entrants competing for a new license, extending the framework by HJM. The license is sold by a regulatory agency through a second price sealed-bid auction. Each incumbent can obtain extra value by adding the license, whereas an entrant can enter the market by acquiring it. We assume complete information, as in HJM. ${ }^{5}$

The set of incumbents is $I \equiv\{1, \ldots, n\}$ with $n \geq 2$. Each incumbent's payoff differs depending on whether a new entry occurs or not, when it loses in the auction. If another incumbent wins, incumbent $i$ earns $\pi_{i}(n)$, but if an entrant wins, it earns a lower payoff $\pi_{i}(n+1)$, that is, $\pi_{i}(n+1)<$ $\pi_{i}(n)$, due to the downstream competition. If incumbent $i$ wins, it earns $w_{i}$. Every entrant earns $w_{e}$ if it wins the license and 0 otherwise.

Although we assume heterogeneous incumbents with differential payoff functions, regardless of whoever wins the license, the "external" effect on the profitability of the other incumbents is identical. More precisely, incumbent profits $\pi_{i}(n)$ do not depend on which incumbent wins the license, which means that incumbents use the new license in a way that does not influence comparative (dis)advantages among the incumbents in the current market. The new license is, for example, used only to deter entry in the current market; it may be used to generate extra profit in the other independent market. By this assumption, the entry-deterring effect of winning the new license for an incumbent is separated from the effects on the profits of the incumbents. This simplification facilitates our investigation into entry deterring incentives of incumbents and their bidding behavior.

We assume that bidders do not use (weakly) dominated strategies in an equilibrium and that when an incumbent ties with an entrant, the incumbent wins, but the standard tie-breaking applies among incumbents.

\footnotetext{
${ }^{4}$ For instance, even for a standard second price auction, bidding a bidder's own valuation is no longer dominant with entry deterrence or other types of externality.

${ }^{5}$ For example, all incumbents and entrants in the model have occupied their positions long enough to know each other well.
} 


\section{Preliminaries}

All entrants are willing to pay up to $w_{e}$ to obtain the license, and under the second price sealed-bid auction, bidding $w_{e}$ is a dominant strategy for all entrants. Incumbent $i$ 's willingness to pay for the license depends on externalities in the downstream competition: she is willing to pay $w_{i}-\pi_{i}(n)$ to win it against another incumbent and $w_{i}-\pi_{i}(n+1)$ to win it against an entrant. We call the former $v_{i} \equiv w_{i}-\pi_{i}(n) i$ 's intrinsic valuation, and the latter $w_{i}-\pi_{i}(n+1) i$ 's preemptive valuation. Using $\Delta \pi_{i} \equiv \pi_{i}(n)-\pi_{i}(n+1)>0$ (profit gain from entry deterrence), the preemptive valuation can be written as $v_{i}+\Delta \pi_{i}$ and is greater than the intrinsic valuation. That is, each incumbent has a greater willingness to pay to win the license against an entrant than against another incumbent.

With $w_{e}$ being a dominant strategy for all entrants, we can focus on bid profiles of the incumbents $b \equiv\left(b_{i}\right)_{i \in I}$ and define incumbent $i$ 's payoff as a function of these bid profiles, $u_{i}: \mathbb{R}_{+}^{n} \rightarrow \mathbb{R}_{+}$. If an incumbent bids at least as much as $w_{e}$, i.e., $\max _{j \in I} b_{j} \geq w_{e}$, each highest-bidding incumbent $i$ obtains the expected payoff

$$
u_{i}(b)=\frac{1}{k}\left[w_{i}-\max _{j \in I \backslash\{i\}} b_{j}\right]+\frac{k-1}{k} \pi_{i}(n),
$$

where $k$ is the number of incumbents that make the same highest bid, and all other incumbents $j \in I$ obtain

$$
u_{j}(b)=\pi_{j}(n)
$$

If no incumbent bids at least as much as $w_{e}$, that is, $\max _{j \in I} b_{j}<w_{e}$, then each incumbent $i$ obtains

$$
u_{i}(b)=\pi_{i}(n+1)
$$

If there is an incumbent with intrinsic valuation above $w_{e}$, that is, $w_{e}<\max _{i \in I} v_{i}$, then this incumbent will always bid at least as high as $w_{e}$, so entry never occurs at any Nash equilibrium. On the other hand, if no incumbent has preemptive valuation at least as high as $w_{e}$, that is, $w_{e}>\max _{i \in I}\left\{v_{i}+\Delta \pi_{i}\right\}$, then all incumbents will always bid below $w_{e}$ and entry occurs for sure at any Nash equilibrium. In what follows, we will consider the non-trivial environment satisfying

$$
\max _{i \in I} v_{i}<w_{e}<\max _{i \in I}\left\{v_{i}+\Delta \pi_{i}\right\}
$$

where no incumbent has innate incentive to bid at least as high as the entrants' valuation $w_{e}$ and at least one incumbent is willing to deter an entry. Hence, the possibility of entry will not be determined uniquely as in the other cases; it varies across numerous equilibria to be analyzed later.

We denote by $H \equiv\left\{j \in I: v_{j}+\Delta \pi_{j}>w_{e}\right\}$ the set of incumbents whose preemptive valuations are greater than the entrants' valuation. It can be shown that for each incumbent not belonging to $H$, any bid weakly greater than $w_{e}$ is weakly dominated. Hence, their strategies are irrelevant in determining the outcome; hence, they may be reduced throughout our analysis.

Lemma 1. For each incumbent $i \notin H$, bidding $b_{i} \geq w_{e}$ is weakly dominated.

The proof of Lemma 1 and most proofs of subsequent results are provided in the appendix. If $|H|=1$, then the unique Nash equilibrium has the single incumbent in $H$ bidding preemptively (higher than or equal to $w_{e}$ ) and winning the license. Hence, the entry can be deterred with 
probability 1, as in Gilbert and Newbery (1982). In what follows, we consider the non-trivial case $|H| \geq 2$; that is, two or more incumbents have preemptive valuations greater than the entrants' valuation. Denote by $B^{i}$ the set of bid profiles where $i$ bids at least as high as $w_{e}$ and all others bid less than $w_{e}$ such that

$$
B^{i} \equiv\left\{b \in \mathbb{R}_{+}^{n}: b_{i} \geq w_{e} \text { and } b_{j}<w_{e} \text { for all } j \neq i\right\}
$$

The complete set of pure strategy Nash equilibria is characterized by $\cup_{i \in H} B^{i}$.

Proposition 1. The set of all pure strategy Nash equilibria is given by $\cup_{i \in H} B^{i}$.

In all these pure strategy equilibria, the incumbent $i \in H$ bidding preemptively (i.e., $b_{i} \geq w_{e}$ ) obtains $w_{i}-w_{e}$, and each of the other incumbents $j \in H$ obtains $\pi_{j}(n)$; the former is lower than the latter, i.e., $w_{i}-w_{e}<\pi_{i}(n)$ by $(1)$. Hence, the cost of entry deterrence is paid only by the preemptive bidder and all the other incumbents free ride on it. Such extremely unequal cost sharing is not qualified as a reasonable prediction of the game when other less unequal cost sharing equilibria also exist. We search for these other equilibria where two or more incumbents share the cost of entry deterrence. In all such equilibria, entry deterring incumbents necessarily adopt "strictly mixed" strategies choosing an entry deterring bid with a probability less than 1, which are referred to as randomized preemption.

\section{Monotonic randomized preemption among heterogeneous in- cumbents}

This section formulates the entry deterrence within mixed-strategy equilibria in which at least two incumbents make entry-deterring bids with positive probability. We call such a mixed-strategy equilibrium a randomized preemption equilibrium. The two lemmas below help us simplify our analysis significantly.

Incumbent $i$ 's mixed strategy is a bid distribution $\sigma_{i}$ over $\mathbb{R}_{+}$. The profile of mixed strategies of $i \in H$ is denoted by $\sigma \equiv\left(\sigma_{i}\right)_{i \in H}$. We first show that in any randomized preemption equilibrium, no entry-deterring incumbent chooses a deterring bid above $w_{e}$ with positive probability.

Lemma 2. For any randomized preemption equilibrium $\sigma$, if $i \in H$ is a bidder participating in preemption, $i$ never bids greater than $w_{e}$, that is, $\operatorname{Pr}^{\sigma_{i}}\left[b_{i}>w_{e}\right]=0$.

Given $\pi_{i}(n)>w_{i}-w_{e}$, each incumbent will be better off if any of the other incumbents deters the entry, implying that no incumbent has an incentive to put probability for a bid higher than $w_{e}$. Hence, the only deterring bid for randomized preemption equilibria is $w_{e}$. In addition, we show that non-deterring bids can also be reduced to a single bid since putting different distributions over non-deterring bids is "irrelevant" in terms of payoffs.

Lemma 3. For all randomized preemption equilibrium $\sigma$, if $\sigma^{\prime}$ is such that $\operatorname{Pr}^{\sigma_{i}}\left[b_{i}=w_{e}\right]=\operatorname{Pr}^{\sigma_{i}^{\prime}}\left[b_{i}=\right.$ $\left.w_{e}\right]$ for all $i \in H$ participating in preemption, then $\sigma^{\prime}$ yields the same payoff to all bidders as $\sigma$.

The two lemmas provide simple representations of all randomized preemptive equilibria. A binary preemptive mixed strategy for $i \in H$, which is a mixed strategy such that incumbent $i$ chooses 
the deterring bid $w_{e}$ with probability $p_{i} \in[0,1)$ and a non-deterring bid $\bar{b}_{i}<w_{e}$ with $1-p_{i}$. As such, a binary preemptive mixed strategy can be represented by $p_{i}$, and its strategy profile by $p \equiv\left(p_{i}\right)_{i \in H}$. By Lemmas 2 and 3, any randomized preemption equilibrium can be represented by a profile of binary preemptive mixed strategies, which greatly simplifies our analysis.

For each $i \in H$, denote by $B_{i} \equiv\left\{w_{e}, \bar{b}_{i}\right\}$ incumbent $i$ 's set of two bids for her binary preemptive mixed strategy. Let $B_{-i} \equiv B_{1} \times \cdots \times B_{i-1} \times B_{i+1} \times \cdots \times B_{|H|}$; for each $b \in \times_{j \in H} B_{j}, b_{-i} \equiv$ $\left(b_{1}, \ldots, b_{i-1}, b_{i+1}, \ldots, b_{|H|}\right)$; and

$$
\mu\left(b_{-i}\right) \equiv\left|\left\{j \in H \backslash\{i\}: b_{j}=w_{e}\right\}\right|
$$

be the number of incumbents bidding $w_{e}$ other than $i$. Let $p_{-i} \equiv\left(p_{h}\right)_{h \in H \backslash\{i\}}$. Given $p_{-i}$, the probability that incumbents choose $b_{-i}$ is

$$
\operatorname{Pr}\left[b_{-i} ; p_{-i}\right]=\prod_{j \in H \backslash\{i\}: b_{j}=w_{e}} p_{j} \times \prod_{j \in H \backslash\{i\}: b_{j}=\bar{b}_{j}}\left(1-p_{j}\right) .
$$

Then, when $b_{-i}$ is chosen, the probability of $i$ 's winning through bidding $w_{e}$ equals $\operatorname{Pr}\left[b_{-i} ; p_{-i}\right] /\left(\mu\left(b_{-i}\right)+\right.$ 1 ) and $i$ 's winning payoff is given by $w_{i}-w_{e}$. The probability of $i$ 's losing after bidding $w_{e}$ equals $\operatorname{Pr}\left[b_{-i} ; p_{-i}\right] \times \mu\left(b_{-i}\right) /\left(\mu\left(b_{-i}\right)+1\right)$ and the payoff equals $\pi_{i}(n)$, since in this case no entrant can win the license. Hence, incumbent $i$ 's expected payoff from bidding $w_{e}$ is

$$
U_{i}\left(w_{e} ; p_{-i}\right) \equiv \sum_{b_{-i} \in B_{-i}} \operatorname{Pr}\left[b_{-i} ; p_{-i}\right]\left(\frac{1}{\mu\left(b_{-i}\right)+1}\left[w_{i}-w_{e}\right]+\frac{\mu\left(b_{-i}\right)}{\mu\left(b_{-i}\right)+1} \pi_{i}(n)\right) .
$$

If, on the other hand, incumbent $i$ bids an amount $\bar{b}_{i}$ below $w_{e}$, the following two cases can arise. When there is another incumbent bidding $w_{e}$, that is, $\mu\left(b_{-i}\right) \geq 1$, there is no entry and incumbent $i$ 's payoff equals $\pi_{i}(n)$; and when all the other incumbents also bid below $w_{e}$, now with probability $\operatorname{Pr}\left[\bar{b}_{-i} ; p_{-i}\right]=\Pi_{j \in H \backslash\{i\}}\left(1-p_{j}\right)$, an entrant wins the license and thus incumbent $i$ 's payoff equals $\pi_{i}(n+1)$. Hence, incumbent $i$ 's expected payoff from bidding $\bar{b}_{i}<w_{e}$ is

$$
\begin{aligned}
U_{i}\left(\bar{b}_{i} ; p_{-i}\right) & \equiv \sum_{b_{-i} \in B_{-i}: \mu\left(b_{-i}\right) \geq 1} \operatorname{Pr}\left[b_{-i} ; p_{-i}\right] \pi_{i}(n)+\operatorname{Pr}\left[\bar{b}_{-i} ; p_{-i}\right] \pi_{i}(n+1) \\
& =\sum_{b_{-i} \in B_{-i}} \operatorname{Pr}\left[b_{-i} ; p_{-i}\right] \pi_{i}(n)-\operatorname{Pr}\left[\bar{b}_{-i} ; p_{-i}\right] \Delta \pi_{i}
\end{aligned}
$$

where the equality follows from adding and subtracting the same term $\operatorname{Pr}\left[\bar{b}_{-i} ; p_{-i}\right] \pi_{i}(n)$ and by $\Delta \pi_{i} \equiv \pi_{i}(n)-\pi_{i}(n+1)>0$. Hence, incumbent $i$ 's net benefit of choosing the deterring bid $w_{e}$ against the non-deterring bid $\bar{b}_{i}$, the difference between the above two payoffs (2) and (3), is

$$
U_{i}\left(w_{e} ; p_{-i}\right)-U_{i}\left(\bar{b}_{i} ; p_{-i}\right)=\sum_{b_{-i} \in B_{-i}} \operatorname{Pr}\left[b_{-i} ; p_{-i}\right] \frac{1}{\mu\left(b_{-i}\right)+1}\left[w_{i}-w_{e}-\pi_{i}(n)\right]+\operatorname{Pr}\left[\bar{b}_{-i} ; p_{-i}\right] \Delta \pi_{i}
$$

which can be rewritten as

$$
\operatorname{Pr}\left[\bar{b}_{-i} ; p_{-i}\right]\left(v_{i}-w_{e}\right)\left\{\sum_{b_{-i} \in B_{-i}} \frac{\operatorname{Pr}\left[b_{-i} ; p_{-i}\right]}{\operatorname{Pr}\left[\bar{b}_{-i} ; p_{-i}\right]}\left(\frac{1}{\mu\left(b_{-i}\right)+1}\right)-\frac{\Delta \pi_{i}}{w_{e}-v_{i}}\right\} .
$$


Note that $\operatorname{Pr}\left[b_{-i} ; p_{-i}\right] / \operatorname{Pr}\left[\bar{b}_{-i} ; p_{-i}\right]$ is well-defined since $p$ is such that $p_{i}<1$, for all $i$. Dividing $i$ 's profit loss from entry $\Delta \pi_{i}$ by $w_{e}-v_{i}$, we define incumbent $i$ 's entry-loss rate, that is,

$$
\lambda_{i} \equiv \frac{\Delta \pi_{i}}{w_{e}-v_{i}} .
$$

Since for all $i \in H, \Delta \pi_{i}>w_{e}-v_{i}$ and $w_{e}-v_{i}>0$ from (1), $\lambda_{i}>1$.

HJM assume homogeneous incumbents, that is, $\Delta \pi_{i}=\Delta \pi_{j}=\Delta \pi$ and $v_{i}=v_{j}=v$ for all $i \neq j$, which implies the identical entry-loss rate among all incumbents. However, the identical entry-loss rate among incumbents does not necessarily imply homogeneous incumbents; clearly, $\lambda_{i}=\lambda_{j}$ may hold for different $\left(v_{i}, \Delta \pi_{i}\right)$ and $\left(v_{j}, \Delta \pi_{j}\right)$. More importantly, we highlight the role of differential entry-loss rates among incumbents and how this difference affects their incentive of preemptive bidding.

For each $i \in H$, let $x_{i} \equiv \frac{p_{i}}{1-p_{i}}$ and $x_{-i} \equiv\left(x_{h}\right)_{h \in H \backslash\{i\}}$. Then $p_{i}>0$ if and only if $x_{i}>0$. The first part in the bracket of (5) can be rewritten as

$$
\sum_{b_{-i} \in B_{-i}} \frac{\operatorname{Pr}\left[b_{-i} ; p_{-i}\right]}{\operatorname{Pr}\left[\bar{b}_{-i} ; p_{-i}\right]}\left(\frac{1}{\mu\left(b_{-i}\right)+1}\right)=\sum_{b_{-i} \in B_{-i}} \prod_{j \in H \backslash\{i\}: b_{j}=w_{e}} x_{j}\left(\frac{1}{\mu\left(b_{-i}\right)+1}\right) .
$$

Let

$$
\Phi\left(x_{-i}\right) \equiv \sum_{b_{-i} \in B_{-i}} \prod_{h \in H \backslash\{i\}: b_{h}=w_{e}} x_{h}\left(\frac{1}{\mu\left(b_{-i}\right)+1}\right) .
$$

Note that for each $i, j \in H$,

$$
\begin{aligned}
\Phi\left(x_{-i}\right) & =x_{j} \sum_{b_{-i} \in B_{-i}: b_{j}=w_{e}} \prod_{h \in H \backslash\{i, j\}: b_{h}=w_{e}} x_{h}\left(\frac{1}{\mu\left(b_{-i}\right)+1}\right) \\
& +\sum_{b_{-i} \in B_{-i}: b_{j}=\bar{b}_{j}} \prod_{h \in H \backslash\{i, j\}: b_{h}=w_{e}} x_{h}\left(\frac{1}{\mu\left(b_{-i}\right)+1}\right)
\end{aligned}
$$

and

$$
\begin{aligned}
\sum_{b_{-i} \in B_{-i}: b_{j}=w_{e}} \prod_{h \in H \backslash\{i, j\}: b_{h}=w_{e}} x_{h}\left(\frac{1}{\mu\left(b_{-i}\right)+1}\right) & =\sum_{b_{-j} \in B_{-j}: b_{i}=w_{e}} \prod_{h \in H \backslash\{i, j\}: b_{h}=w_{e}} x_{h}\left(\frac{1}{\mu\left(b_{-j}\right)+1}\right) ; \\
\sum_{b_{-i} \in B_{-i}: b_{j}=\bar{b}_{j}} \prod_{h \in H \backslash\{i, j\}: b_{h}=w_{e}} x_{h}\left(\frac{1}{\mu\left(b_{-i}\right)+1}\right) & =\sum_{b_{-j} \in B_{-j}: b_{i}=\bar{b}_{i}} \prod_{h \in H \backslash\{i, j\}: b_{h}=w_{e}} x_{h}\left(\frac{1}{\mu\left(b_{-j}\right)+1}\right) .
\end{aligned}
$$

Since we factor out $v_{i}-w_{e}<0$ for each $i$ in (5), the net benefit of the deterring bid is positive, i.e., $U_{i}\left(w_{e} ; p_{-i}\right)-U_{i}\left(\bar{b}_{i} ; p_{-i}\right)>0$ if and only if

$$
\Phi\left(x_{-i}\right)<\lambda_{i},
$$

and the net benefit of the non-deterring bid (so free-riding) is positive if and only if

$$
\Phi\left(x_{-i}\right)>\lambda_{i} .
$$


Note that (11) shows that an incumbent with a greater entry-loss rate is more likely to choose the deterring bid. Suppose that $\lambda_{i} \geq \lambda_{j}$ and the same probability of entry-deterrence at both $x_{-i}$ and $x_{-j}$, so $\Phi\left(x_{-i}\right)=\Phi\left(x_{-j}\right)$. Then, whenever (11) holds for $j,(11)$ also holds for $i$; but the converse does not hold. That is, whenever $j$ is willing to choose the deterring bid, $i$ is also willing to do the same, but the converse does not hold.

When (11) holds, it is optimal for incumbent $i$ to choose the deterring bid (all the other incumbents bid an amount below $w_{e}$ ), which must not be a case at a randomized preemption equilibrium. Hence, in order to incentivize randomized participation of two or more incumbents in entry deterrence, all incumbents are to be provided free-riding incentive, that is, $x$ satisfies, for all $i \in H$,

$$
\Phi\left(x_{-i}\right) \geq \lambda_{i}
$$

If the inequality holds strictly for incumbent $i \in H$, the incentive is too strong, so the incumbent free rides fully and does not bid preemptively, $p_{i}=0$. Hence, any incumbent bidding preemptively with $p_{i}>0$ must be given a balanced incentive, satisfying (13) with equality. Note that giving a balanced incentive for an incumbent with a higher entry-loss rate is more costly for the other incumbents since to make the left-hand side of (13) equal to her entry-loss rate, the other incumbents need to engage in the preemptive bidding with greater probability.

If any profile of binary preemptive mixed strategies $\left(p_{i}^{*}\right)_{i \in H}$ constitutes an equilibrium, then for each $i \in H$, (13) holds and for each $i \in H$ with $p_{i}^{*}>0$,

$$
\Phi\left(x_{-i}^{*}\right)=\lambda_{i} .
$$

Using (8), (9) and (10), for any two incumbents $i, j \in H$ with $p_{i}^{*}, p_{j}^{*}>0$,

$$
\begin{aligned}
\Phi\left(x_{-i}^{*}\right)-\Phi\left(x_{-j}^{*}\right) & =\left(x_{j}^{*}-x_{i}^{*}\right) \sum_{b_{-i} \in B_{-i}: b_{j}=w_{e}} \prod_{h \in H \backslash\{i, j\}: b_{h}=w_{e}} x_{h}^{*}\left(\frac{1}{\mu\left(b_{-i}\right)+1}\right) \\
& =\lambda_{i}-\lambda_{j} .
\end{aligned}
$$

Hence, using (14) and (15), $x_{j}^{*} \geq x_{i}^{*}$ if and only if $\lambda_{i} \geq \lambda_{j}$, that is, $p_{j}^{*} \geq p_{i}^{*}$ if and only if $\lambda_{i} \geq \lambda_{j}$. That is, incumbent $i$ with a higher entry-loss rate bids less aggressively than incumbent $j$ with a lower entry-loss rate. Therefore, we obtain Proposition 2.

Proposition 2. Given any randomized preemption equilibrium represented by binary preemptive mixed strategies $\left(p_{i}^{*}\right)_{i \in H}$, for any pair of incumbents $i, j \in H$ who participate in preemptive bidding $\left(p_{i}^{*}, p_{j}^{*}>0\right), p_{i}^{*} \geq(>) p_{j}^{*}$ if and only if $\lambda_{i} \leq(<) \lambda_{j}$.

To give an intuition, recall that in any randomized preemption equilibrium, any incumbent participating in entry deterrence should be provided a balanced incentive of free-riding, namely, indifference between preemptive bidding and free-riding, as stated by (14). Since an incumbent with a higher entry-loss rate also has a greater incentive of preemption as explained earlier, to make her indifferent between preemptive bidding and free-riding, the other incumbents needs to give her enough incentive of free-riding, which is possible when they choose preemptive bidding with sufficiently high probabilities according to (13). The higher the entry-loss rate, which is the 
right-hand side of (14), the greater the probabilities of preemptive bidding by the other participating incumbents in the left-hand side of (14). ${ }^{6}$

\section{Existence of equilibria with fully or partially participating ran- domized preemption}

We now investigate existence of equilibria with randomized preemption. Though we consider heterogeneous incumbents, most of our results in this section and the next are obtained under the condition of bounded heterogeneity. For each $\lambda_{0}>0$ and each $\delta>0$, a profile of entry-loss rates $\lambda \equiv\left(\lambda_{i}\right)_{i \in H}$ with the mean entry-loss rate $\lambda_{0}$ exhibits bounded heterogeneity below $\delta$ if the variance of the entry-loss rates in $\lambda$ is below $\delta$. When a result holds for all $\lambda$ with mean entry-loss rate $\lambda_{0}$ under the condition of bounded heterogeneity below some $\delta>0$, we say the result holds for all boundedly heterogeneous profiles of entry-loss rates with mean $\lambda_{0}$.

A fully participating randomized preemption equilibrium, or briefly FPRP equilibrium, is a mixed strategy Nash equilibrium where every incumbent in $H$ participates in entry deterrence with a positive probability of preemptive bidding. For an identical entry-loss rate $\lambda_{0}$, from (14), an FPRP equilibrium exists if there is $x_{0}^{*}$ such that $x_{0}^{*}=x_{h}$ for all $h \in H$ and $x_{0}^{*}$ is a solution of

$$
\Phi(\underbrace{x_{0}, \ldots, x_{0}}_{|H|-1 \text { elements }})=\lambda_{0} .
$$

The existence of an FPRP equilibrium with non-identical entry-loss rates is guaranteed, as we state in the next proposition, when there are only two incumbents in $H$ or when the entry-loss rates of all incumbents in $H$ exhibit bounded heterogeneity.

Proposition 3. (i) If $|H|=2$, then for all entry-loss rates $\lambda_{1}, \lambda_{2}$ of the two incumbents in $H$, there exists a unique FPRP equilibrium.

(ii) Assume $|H| \geq 3$. For all entry-loss rates $\lambda_{0}$ and all boundedly heterogeneous profiles of entry-loss rates with the mean $\lambda_{0}$, there exists a unique FPRP equilibrium.

Note that in the two-incumbent case, no extra condition of bounded heterogeneity is needed for the existence. When there are three or more incumbents in $H$, the existence is guaranteed under the condition of bounded heterogeneity in entry-loss rates. If this condition is not satisfied (for instance, incumbent $i$ 's entry-loss rate $\lambda_{i}$ is too high for the other incumbents to compensate it), then an FPRP equilibrium may not exist, as shown by the following three-incumbent example.

Example 1. Let $H \equiv\{1,2,3\}$ and consider the case $\Phi(\cdot)$ in (8) is given by: for all $a, b, \Phi(a, b)=$ $\frac{1}{3} a b+\frac{1}{2} a+\frac{1}{2} b+1$. If there is an FPRP equilibrium, then at the equilibrium, $\left(x_{1}, x_{2}, x_{3}\right)$ satisfies (14), that is, $\Phi\left(x_{2}, x_{3}\right)=\lambda_{1}, \Phi\left(x_{1}, x_{3}\right)=\lambda_{2}, \Phi\left(x_{1}, x_{2}\right)=\lambda_{3}$. The three equations imply that for all $i \in\{1,2,3\}$,

$$
x_{i}^{*}=\frac{3-12 \lambda_{i}+\sqrt{3\left(4 \lambda_{1}-1\right)\left(4 \lambda_{2}-1\right)\left(4 \lambda_{3}-1\right)}}{8 \lambda_{i}-2} .
$$

Now suppose that $\lambda_{1}=\lambda_{2}=2$ and $\lambda_{3}=5$. Then $x_{3}^{*}<0$, which shows that no FPRP exists.

\footnotetext{
${ }^{6}$ Note that the left-hand side of (14) is increasing in the probabilities of deterring bids by the other participating incumbents.
} 
If the entry-loss rates of all incumbents in $H$ are identical, then the FPRP equilibrium is symmetric (all incumbents in $H$ adopt an identical deterring probability). Moreover, as stated in the next corollary, homogeneity of entry-loss rate is a necessary and sufficient condition for the existence of a (unique) symmetric FPRP equilibrium.

Corollary 1. Assume $|H| \geq 3$. A (unique) symmetric FPRP equilibrium exists if and only if the entry-loss rates of all incumbents in $H$ are identical.

This corollary follows directly from Propositions 2 and 3. The proposition and its corollary generalize existence of symmetric FPRP equilibrium by HJM (Proposition 1 in HJM) in two respects. First, homogeneity of the incumbents is not needed for existence of FPRP equilibrium. We obtain the same existence result under the assumption of bounded heterogeneity of entry-loss rates. Second, we identify a necessary and sufficient condition (homogeneous entry-loss rate) for the existence of symmetric FPRP equilibrium.

We now turn to equilibria where not all incumbents in $H$ participate in entry deterrence. A partially participating randomized preemption $(P P R P)$ equilibrium is a mixed strategy Nash equilibrium where two or more incumbents in $H$ participate in entry deterrence with a positive probability of preemptive bidding. When all these participating incumbents adopt the same probability of preemptive bidding, the PPRP equilibrium is referred to as a symmetric PPRP equilibrium. It is not fully symmetric, though, since participating and non-participating incumbents adopt different strategies.

As for the FPRP equilibrium in Proposition 3, the existence of the PPRP equilibrium requires a condition of bounded heterogeneity among the participating incumbents. To begin with, let $S \subseteq H$ be the set of the participating incumbents who have an identical entry-loss rate $\lambda_{0}$. Under an identical entry-loss rate of participating incumbents, Proposition 2 implies symmetry of the PPRP equilibrium. Then, a symmetric PPRP equilibrium with this set $S$ exists if (13) holds and for all $i \in S$, (14) holds; that is, it is optimal for the other non-participating incumbents to choose non-deterring bids and all participating incumbents $i \in S$ choose $x$ that makes them indifferent between choosing the deterring bid and a non-deterring bid (free-riding) indifferent. Note that (14) for the symmetric PPRP can be simplified as follows: for all $i \in S$,

$$
\sum_{k=0}^{|S|-1} \frac{1}{k+1}\left(\begin{array}{c}
|S|-1 \\
k
\end{array}\right) x^{k}=\lambda_{0} .
$$

It can be shown that if $i \in H \backslash S$ has $\lambda_{i}>\lambda_{0}$, then both (13) and (17) cannot be satisfied. Hence, an additional condition on entry-loss rates of participating and non-participating incumbents is needed to establish the existence of PPRP. It is that participating incumbents' entry-loss rates are not dominated by the entry-loss rate of a non-participating incumbent. Denote by $\lambda_{S}$ a profile of entry-loss rates of all incumbents in $S$. To establish the existence of a PPRP equilibrium under the condition of bounded heterogeneity among participating incumbents, we must have a general version of (17) with heterogeneous entry-loss rates from $\lambda_{S}$.

Proposition 4. (i) If $|S|=2$ and $\arg \max _{i \in H} \lambda_{i} \cap S \neq \emptyset$, there exists a unique PPRP equilibrium with the group of participating incumbents $S$. 
(ii) Assume $|S| \geq 3$. For all $\lambda_{0}$ and all boundedly heterogeneous profiles $\lambda_{S}$ with the mean $\lambda_{0}$, if for all $i \in H \backslash S, \lambda_{i} \leq \max \left\{\lambda_{j}: j \in S\right\}$, then there exists a PPRP equilibrium with the group of participating incumbents $S$.

In both parts, we need extra conditions for the existence of a PPRP equilibrium. When $|S|=2$, at least one participating incumbent must have an entry-loss rate weakly greater than those of all other non-deterring incumbents. When $|S| \geq 3$, all participating incumbents must have entry-loss rates with bounded heterogeneity and their maximum rate should not be lower than the entryloss rate of any non-participating incumbent. The next example shows that these conditions are indispensible.

Example 2. The previous example can be extended to prove that the existence of Part 2 is not guaranteed without the condition on entry-loss rates. Now, we show that the existence in Part 1 is not guaranteed without the condition on entry-loss rates in Part 1. We modify Example 1 and let $\lambda_{1}=\lambda_{2}=2$, and $\lambda_{3}>2$. It follows from Proposition 4 that there are PPRP equilibria for two incumbents including the highest entry-loss incumbent, $S=\{1,3\}$ and $S^{\prime}=\{2,3\}$, but the existence of an equilibrium without incumbent $3, S^{\prime \prime}=\{1,2\}$, is not guaranteed for a sufficiently large $\lambda_{3}$. To prove this, given $\lambda_{1}=\lambda_{2}=2$, we have $x_{1}^{*}=x_{2}^{*}=2$. Then, for incumbent 3 , $\Phi\left(x_{1}^{*}, x_{2}^{*}\right)-\lambda_{3}=\frac{4}{3}+1+1+1-\lambda_{3}$. Hence, if $\lambda_{3}>13 / 3$, then $\Phi\left(x_{1}^{*}, x_{2}^{*}\right)-\lambda_{3}<0$, so incumbent 3's net benefit of the deterring bid is positive, and it is optimal for her to choose a deterring bid with probability 1 , which means that a PPRP equilibrium with the set of deterring incumbents $\{1,2\}$ does not exist.

If incumbents exhibit bounded heterogeneity, there exists a unique FPRP, as stated in Proposition 3. However, there can still exist multiple PPRP equilibria; so no uniqueness is stated in Proposition 4.

By examining a special case of Proposition 4 where all incumbents in $H$ have an identical entry-loss rate, we can obtain a corollary that is comparable to Proposition 2 by HJM.

Corollary 2. If $\lambda_{i}=\lambda_{0}$ for each $i \in H$, then for each $S \subseteq H$, there exists a PPRP equilibrium with the set of participating incumbents $S$. And as $|S| \leq|H|$ increases, the entry probability in the PPRP with the group of participating incumbents $S$ increases.

The corollary compares different PPRP equilibria in a model while HJM's result compares unique symmetric FPRP equilibria in "different models" with varying numbers of identical incumbents. This corollary says that the cost of free riding (probability of entry) increases as the number of incumbents participating in preemptive bidding increases. Hence, there is a trade-off between the efficiency of the entry deterrence and the fairness of the allocation of deterring cost among the incumbents.

\section{One leader and many followers}

By Proposition 4, a PPRP equilibrium may not exist for more than two actively participating incumbents if their entry-loss rates are too heterogeneous. We now consider a bipartite group case where a PPRP equilibrium may exist without the bounded heterogeneity condition. 
Let $S \subseteq H$ be the bipartite group consisting of a single "leader" and $|S|-1$ "followers". The leader's entry-loss rate is denoted by $\lambda_{l}$ and the followers' entry-loss rates are identical and denoted by $\lambda_{f}$. Assume that all the other incumbents have an entry-loss rate lower than both $\lambda_{l}$ and $\lambda_{f}$, that is, for all $j \in H \backslash S, \lambda_{j}<\min \left\{\lambda_{l}, \lambda_{f}\right\}$. We call any PPRP equilibrium with the set of participating incumbents $S$ a leader-follower PPRP equilibrium.

To investigate existence and the nature of the leader-follower PPRP equilibrium, let $x_{l} \equiv$ $\frac{p_{l}}{1-p_{l}}$, and $x_{f} \equiv \frac{p_{f}}{1-p_{f}}$, where $p_{l}$ is the leader's probability of choosing the deterring bid and $p_{f}$ the followers'. Then, by (13) and (14), a leader-follower PPRP equilibrium exists if each follower chooses $x_{f}^{*}$ so that the leader is indifferent between making a deterring bid and making a non-deterring bid, that is,

$$
\sum_{k=0}^{|S|-1} \frac{1}{k+1}\left(\begin{array}{c}
|S|-1 \\
k
\end{array}\right) x_{f}^{* k}=\lambda_{l}
$$

and given $x_{f}^{*}$, the leader chooses $x_{l}^{*}$ so that each follower is indifferent between making a deterring bid and making a non-deterring bid, that is,

$$
x_{l}^{*} \sum_{k=0}^{|S|-2} \frac{1}{k+2}\left(\begin{array}{c}
|S|-2 \\
k
\end{array}\right) x_{f}^{* k}+\sum_{k=0}^{|S|-2} \frac{1}{k+1}\left(\begin{array}{c}
|S|-2 \\
k
\end{array}\right) x_{f}^{* k}=\lambda_{f}
$$

and finally all the other incumbents optimally choose zero entry deterring probability. We now state our result on existence of PPRP equilibrium.

Proposition 5. Let $S$ be a set of a single leader with entry-loss rate $\lambda_{l}$ and followers with entry-loss rate $\lambda_{f}$.

(i) If $\lambda_{l}<\lambda_{f}$, then there exists a leader-follower PPRP equilibrium. In all these PPRP, the leader bids more aggressively, that is, $0<p_{f}^{*}<p_{l}^{*}$.

(ii) If $\lambda_{l}>\lambda_{f}$, then there may not exist a leader-follower PPRP equilibrium; if any, the followers bid more aggressively than the leader, $p_{f}^{*}>p_{l}^{*}>0$.

In case (i), we do not need an additional condition, the bounded heterogeneity condition of Proposition 4 to obtain equilibrium existence; a solution for simultaneous equations, (18) and (19) exists in case (i). However, in case (ii), a solution may not exist. This is because when $\lambda_{l}$ is too large, $x_{f}^{*}$ of (18) also increases too high so that $x_{l}^{*}$ of (19) must be negative, which is not an admissible value for probability ratio $x_{l}^{*}$. Nevertheless, in addition, if $\lambda_{l}$ and $\lambda_{f}$ are sufficiently close, by Proposition 4, a leader-follower PPRP equilibrium in case (ii) exists. We will show in Sections 6.1 and 6.2 when the two cases arise using concrete examples of Cournot and Stackelberg competitions.

Note that this result applies when all the other incumbents outside $S$ have lower entry-loss rates than $\lambda_{l}$ and $\lambda_{f}$. Without this assumption, the existence result is not guaranteed.

We now give a numerical example of the leader-follower PPRP equilibrium in Proposition 5.

Example 3. Example 1 can be reframed for this section. Let $S$ be now a subset of $H$, where $S=\{1,2,3\}$, and each $j \in H \backslash S$ has an entry-loss rate lower than all from $S$. Suppose that 
incumbent 1 and 2 are followers and incumbent 3 is the leader. Then, from (18), we have

$$
\sum_{k=0}^{|S|-1} \frac{1}{k+1}\left(\begin{array}{c}
|S|-1 \\
k
\end{array}\right) x_{f}^{* k}=1+x_{f}^{*}+\frac{1}{3} x_{f}^{* 2}=\lambda_{l},
$$

which yields $x_{f}^{*}=\frac{-3+\sqrt{3\left(4 \lambda_{l}-1\right)}}{2}$; and from (19),

$x_{l}^{*} \sum_{k=0}^{|S|-2} \frac{1}{k+2}\left(\begin{array}{c}|S|-2 \\ k\end{array}\right) x_{f}^{* k}+\sum_{k=0}^{|S|-2} \frac{1}{k+1}\left(\begin{array}{c}|S|-2 \\ k\end{array}\right) x_{f}^{* k}=x_{l}^{*}\left(\frac{1}{2}+\frac{1}{3} x_{f}^{*}\right)+\left(1+\frac{1}{2} x_{f}^{*}\right)=\lambda_{f}$,

which can be rewritten as $x_{l}^{*}=x_{f}^{*}+\frac{-4\left(1+x_{f}^{*}+\frac{1}{3} x_{f}^{* 2}\right)+4 \lambda_{f}}{\left(2+\frac{4}{3} x_{f}^{*}\right)}=x_{f}^{*}+\frac{-4\left(\lambda_{l}-\lambda_{f}\right)}{\left(2+\frac{4}{3} x_{f}^{*}\right)}=-\frac{3}{2}+\frac{\left(4 \lambda_{f}-1\right) \sqrt{3\left(4 \lambda_{l}-1\right)}}{2\left(4 \lambda_{l}-1\right)}$, where the last equality follows from $2+\frac{4}{3} x_{f}^{*}=\frac{2\left(4 \lambda_{l}-1\right)}{\sqrt{3\left(4 \lambda_{l}-1\right)}}$. One can confirm that this solution is consistent with the one from Example 1.

\subsection{Cournot Competition}

Consider an industry with one leader and $n-1$ followers. These $n$ incumbent firms choose their quantities of output independently to maximize their profits under the linear market demand $p(Q)=a-b Q$. Assume that the leader has a constant marginal cost $c_{l}$ and each follower also has a common constant marginal cost $c_{f}$ such that $a>c_{i}>0$ for all $i=l, f$, and $b>0$.

In this industry, a regulatory agency seeks to sell a new license to an incumbent or an entrant. If an incumbent wins the license, the winning firm can earn extra profit or reduce its fixed cost, which is represented by her intrinsic valuation $v_{l}=w_{l}-\pi_{l}(n)$ and $v_{f}=w_{f}-\pi_{f}(n) .{ }^{7}$ If an entrant wins the license, she enters the Cournot competition with the same cost function as the follower.

We solve two Cournot models, one without entry and the other with entry. Then, the profit gains from entry deterrence of the leader and a follower, $\Delta \pi_{l}$ and $\Delta \pi_{f}$ are given by

$$
\begin{aligned}
\Delta \pi_{l} & =\frac{\left(a-n c_{l}+(n-1) c_{f}\right)^{2}}{b(n+1)^{2}}-\frac{\left(a-(n+1) c_{l}+n c_{f}\right)^{2}}{b(n+2)^{2}}, \\
\Delta \pi_{f} & =\frac{\left(a-2 c_{f}+c_{l}\right)^{2}}{b(n+1)^{2}}-\frac{\left(a-2 c_{f}+c_{l}\right)^{2}}{b(n+2)^{2}} .
\end{aligned}
$$

In addition, the entrant's payoff $w_{e}$ is given by

$$
w_{e}=\frac{\left(a-2 c_{f}+c_{l}\right)^{2}}{b(n+2)^{2}} .
$$

The leader's entry-loss rate $\lambda_{l}=\frac{\Delta \pi_{l}}{w_{e}-v_{l}}$ and the (incumbent) follower's entry-loss rate $\lambda_{f}=\frac{\Delta \pi_{f}}{w_{e}-v_{f}}$ are both greater than 1 and the intrinsic valuation is positive, as required in Section 3, if parameter $a$ is chosen suitably.

Denote further $\Delta_{l, f} c \equiv c_{l}-c_{f}$ and $\Delta_{l, f} v \equiv v_{l}-v_{f}$ to identify conditions under which the first or the second case of Proposition 5 holds. Fix $c_{f}$ and $v_{f}$. Then, we may write $c_{l}$ and $v_{l}$

\footnotetext{
${ }^{7}$ Specifically, we can let the extra margin the incumbent leader (or a follower) gains from winning a license be $d_{l}>0$ (or $d_{f}>0$, respectively). By construction, the leader's intrinsic valuation is $v_{l}=w_{l}-\pi_{l}(n)=d_{l}$ and each follower's is $v_{f}=w_{f}-\pi_{f}(n)=d_{f}$.
} 
as $c_{l}=c_{f}+\Delta_{l, f} c$ and $v_{l}=v_{f}+\Delta_{l, f} v$. The difference in the two entry-loss rates, $\lambda_{l}-\lambda_{f}$, is strictly decreasing in $\Delta_{l, f} c$ and is strictly increasing in $\Delta_{l, f} v$ at $\Delta_{l, f} c=0$ and $\Delta_{l, f} v=0$, if $a$ is large enough. Furthermore, the difference is strictly increasing in $\Delta_{l, f} v$ but is not monotonic with respect to changes in $\Delta_{l, f} c$ due to the square terms in the formulas for $\lambda_{l}$ and $\lambda_{f}$, that is, $\Delta \pi_{l}$ and $\Delta \pi_{f}$ as well as $w_{e}$. Hence, both cases (i) and (ii) in Proposition 5 can arise by increasing either $\Delta_{l, f} c$ or $\Delta_{l, f} v$. For example, if $\Delta_{l, f} c=0$, any positive value $\Delta_{l, f} v$ yields a higher entry-loss rate for the leader, i.e., $\lambda_{l}>\lambda_{f}$, but any negative value $\Delta_{l, f} v$ yields a lower entry-loss rate for the leader, i.e., $\lambda_{l}<\lambda_{f}$.

Assuming $c_{f}=v_{f}=1$, the locus of two parameters $c_{l}$ and $v_{l}$ satisfying $\lambda_{l}=\lambda_{f}$ is given by a curve in Figure 1-(a). Parameter values above (or below) the curve give $\lambda_{l}>\lambda_{f}$ (or $\lambda_{l}<\lambda_{f}$, respectively); hence, the leader bids less (or more) aggressively than the followers.

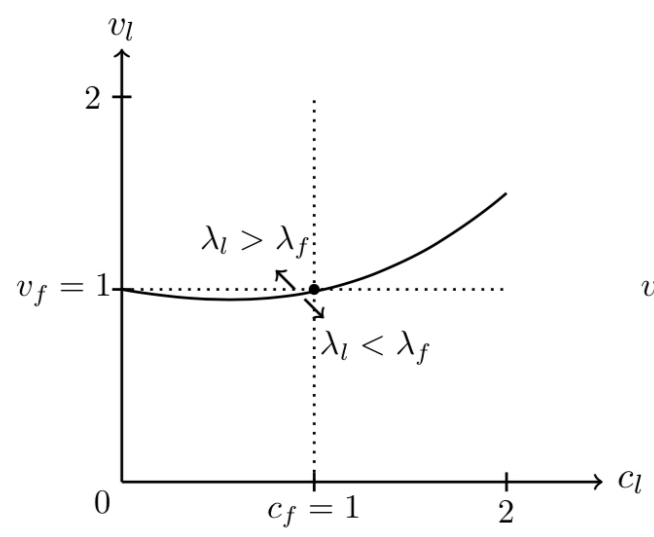

(a)

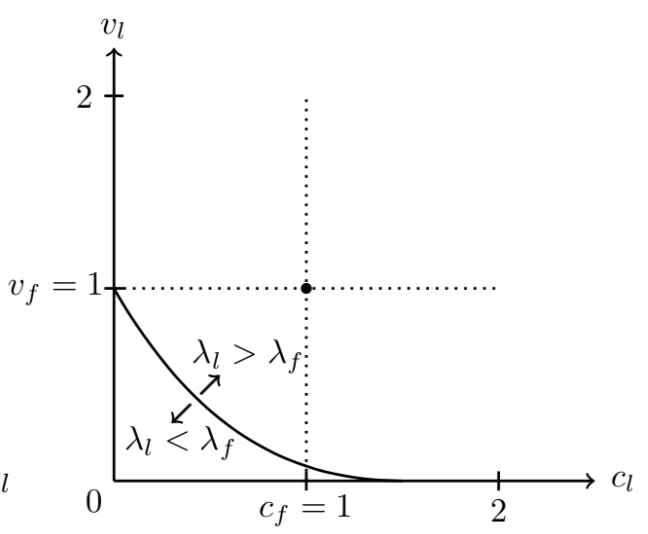

(b)

Figure 1: Comparison of two entry loss rates in Cournot model (a) and Stackelberg models (b)

\subsection{Stackelberg Competition}

Now, we suppose that the leader moves first, in addition to the difference in their benefits from winning a license and costs as assumed in Section 6.1. By solving the Stackelberg competition with or without entry, it can be readily shown that the profit gains from entry deterrence of the leader and the followers, $\Delta \pi_{l}$ and $\Delta \pi_{f}$ are given by

$$
\begin{aligned}
\Delta \pi_{l} & =\frac{\left(a-n c_{l}+(n-1) c_{f}\right)^{2}}{4 b n}-\frac{\left(a-(n+1) c_{l}+n c_{f}\right)^{2}}{4 b(n+1)} \\
\Delta \pi_{f} & =\frac{\left(a-(n+1) c_{f}+n c_{l}\right)^{2}}{4 b n^{2}}-\frac{\left(a-(n+2) c_{f}+(n+1) c_{l}\right)^{2}}{4 b(n+1)^{2}}
\end{aligned}
$$

In addition, the entrant's payoff $w_{e}$ is given by

$$
w_{e}=\frac{\left(a-(n+2) c_{f}+(n+1) c_{l}\right)^{2}}{4 b(n+1)^{2}} .
$$


We can choose $a$ so that both entry-loss rates of the leader and the followers, $\lambda_{l}=\frac{\Delta \pi_{l}}{w_{e}-v_{l}}$ and $\lambda_{f}=\frac{\Delta \pi_{f}}{w_{e}-v_{f}}$ are greater than 1 and the intrinsic valuation is positive.

The difference between the Cournot model and the Stackelberg model is that in the latter, even with $\Delta_{l, f} c=0$ and $\Delta_{l, f} v=0$, the difference in the two entry-loss rates, $\lambda_{l}-\lambda_{f}$, is positive, because of the first mover's advantage in the Stackelberg competition. Hence, Case (ii) of Proposition 5 $\left(\lambda_{l}>\lambda_{f}\right)$ is more likely to arise than in the Cournot competition. For example, if $\Delta_{l, f} c=0$, any value of $\Delta_{l, f} v$ greater than or equal to a negative lower bound yields a higher entry-loss rate for the leader $\left(\lambda_{l}>\lambda_{f}\right)$, so case (ii) of Proposition 5 holds. And any value of $\Delta_{l, f} v$ lower than the negative lower bound yields a lower entry-loss rate for the leader $\left(\lambda_{l}<\lambda_{f}\right)$, so case (i) of Proposition 5 holds.

Assuming $c_{f}=v_{f}=1$, the locus of two parameters $c_{l}$ and $v_{l}$ satisfying $\lambda_{l}=\lambda_{f}$ is given by a curve in Figure 1-(b). Parameter values above (or below, respectively) the curve give $\lambda_{l}>\lambda_{f}$ (or $\lambda_{l}<\lambda_{f}$ ); hence the leader bids less (or more) aggressively than the followers.

\subsection{Policy implications}

In designing a license auction, policy makers often consider limiting participation of some incumbents, in particular, market leaders in order to reduce the competitive disadvantage of the followers or entrants in the downstream industry. In this subsection, we consider the leader-follower model in Section 6 and evaluate the policy of excluding the leader in the license auction. In the model with identical incumbents by HJM, excluding an incumbent always leads to a lower probability of entry; so either exclusion of all incumbents or none is desired. Our model with heterogeneous incumbents leads to more diverse possibilities; the policy of excluding the leader may be desirable in some situations such that excluding the leader leads to a higher probability of entry.

Suppose a regulatory agency considers the policy to exclude the leader for the purpose of increasing entry probability, which enhances competition in the downstream. Without the leader, there are $|S|-1$ incumbent followers, and the probability of choosing the deterring bid, denoted by $\hat{p}_{f}$, satisfies the equilibrium condition like (17) but with only $|S|-1$ incumbents. By a binomial expansion as in proof of Corollary 2, the formula can be rewritten as

$$
\frac{\left(1+\hat{x}_{f}\right)^{(|S|-1)}-1}{\hat{x}_{f}(|S|-1)}=\lambda_{f},
$$

where $\hat{x}_{f} \equiv \frac{\hat{p}_{f}}{1-\hat{p}_{f}}$. If the regulatory agency executes the policy of limiting the leader's participation, the entry probability can be rewritten in terms of $\hat{x}_{f}$ by

$$
\left(1-\hat{p}_{f}\right)^{|S|-1}=\frac{1}{\left(1+\hat{x}_{f}\right)^{|S|-1}} .
$$

Without such regulatory intervention, a leader-follower PPRP equilibrium $\left(p_{l}^{*}, p_{f}^{*}\right)$ satisfies the two conditions (18) and (19). As we show in the proof of Proposition 6, the two conditions can be rewritten as

$$
\frac{\left(1+x_{f}^{*}\right)^{|S|}-1}{x_{f}^{*}|S|}=\lambda_{l},
$$


and

$$
x_{l}^{*}\left[\frac{\left(1+x_{f}^{*}\right)^{|S|-1}}{x_{f}^{*}(|S|-1)}-\frac{\left(1+x_{f}^{*}\right)^{|S|}-1}{\left(x_{f}^{*}\right)^{2}|S|(|S|-1)}\right]+\frac{\left(1+x_{f}^{*}\right)^{(|S|-1)}-1}{x_{f}^{*}(|S|-1)}=\lambda_{f},
$$

where $x_{i}^{*} \equiv p_{i}^{*} /\left(1-p_{i}^{*}\right)$ for $i=l, f$. The entry probability is given by

$$
\left(1-p_{l}^{*}\right)\left(1-p_{f}^{*}\right)^{|S|-1}=\frac{1}{\left(1+x_{l}^{*}\right)\left(1+x_{f}^{*}\right)^{|S|-1}} .
$$

We identify conditions under which this entry probability is higher than that of the leader-follower PPRP equilibrium analyzed earlier.

Proposition 6. Let $S$ be a set of a single leader with entry-loss rate $\lambda_{l}$ and followers with identical entry-loss rate $\lambda_{f}$.

(i) If a leader-follower PPRP equilibrium exists and satisfies $\lambda_{l} x_{l}^{*}+\lambda_{f}(|S|-1)\left(x_{f}^{*}-\hat{x}_{f}\right)<0$, then limiting the leader's participation decreases the entry probability.

(ii) If a leader-follower PPRP equilibrium exists and satisfies $\lambda_{l} x_{l}^{*}+\lambda_{f}(|S|-1)\left(x_{f}^{*}-\hat{x}_{f}\right)>0$ or a leader-follower PPRP equilibrium does not exist with a sufficiently large $\lambda_{l}$, then limiting the leader's participation increases the entry probability.

Even when there is no leader-follower PPRP with the set $S$ due to the leader's entry-loss rate being sufficiently higher than each follower's based on Proposition 5 (ii), there can be a leaderfollower PPRP with a subset of $S$. In this case, with the leader, if $\lambda_{l}$ is sufficiently large, the entry probability is lower than that from limiting the leader's participation. On the other hand, without the leader, the remaining incumbents are identical, i.e., followers, so by Proposition 4, there exists a symmetric PPRP with them. Unlike Corollary 3, Proposition 6 demonstrates that the bidder asymmetry plays a key role in deriving policy implications.

Example 4. Consider the three-incumbent case of Example 3. It is possible to find the entry probability in a closed form, which is given by

$$
\frac{1}{\left(-\frac{1}{2}+\frac{\sqrt{3}}{2} \sqrt{4 \lambda_{l}-1}\right)^{2}\left(-\frac{1}{2}+\frac{\sqrt{3}}{2} \frac{\left(4 \lambda_{f}-1\right)}{\sqrt{4 \lambda_{l}-1}}\right)} .
$$

When there are only two followers, excluding the leader, we obtain the entry probability as

$$
\frac{1}{\left(2 \lambda_{f}-1\right)^{2}}
$$

The closed form solution enables us to strengthen the results of Proposition 6, without additional conditions, such that if there is a leader-follower PPRP equilibrium with the set $S$, limiting the leader's participation decreases the entry probability, whereas if there is no leader-follower PPRP equilibrium with the set $S$, limiting the leader's participation increases the entry probability. It can be readily shown that for a fixed follower's entry-loss rate $\lambda_{f}$, the entry probability without excluding the leader is greater than that with excluding the leader if the leader's entry-loss rate $\lambda_{l}$ is lower than a threshold, and moreover, it is strictly decreasing in $\lambda_{l}$. More interestingly, however, if the leader's entry-loss rate $\lambda_{l}$ is higher than the threshold $\lambda_{l}^{\dagger}$ in Figure 2, there is no leader-follower 
PPRP equilibrium with two followers, and the entry probability with the leader and one follower is lower than that with limiting the leader's participation. If $\lambda_{f}=2$, the threshold is given as $\lambda_{l}^{\dagger}=\frac{13}{3}$. The comparison is described in Figure 2 .

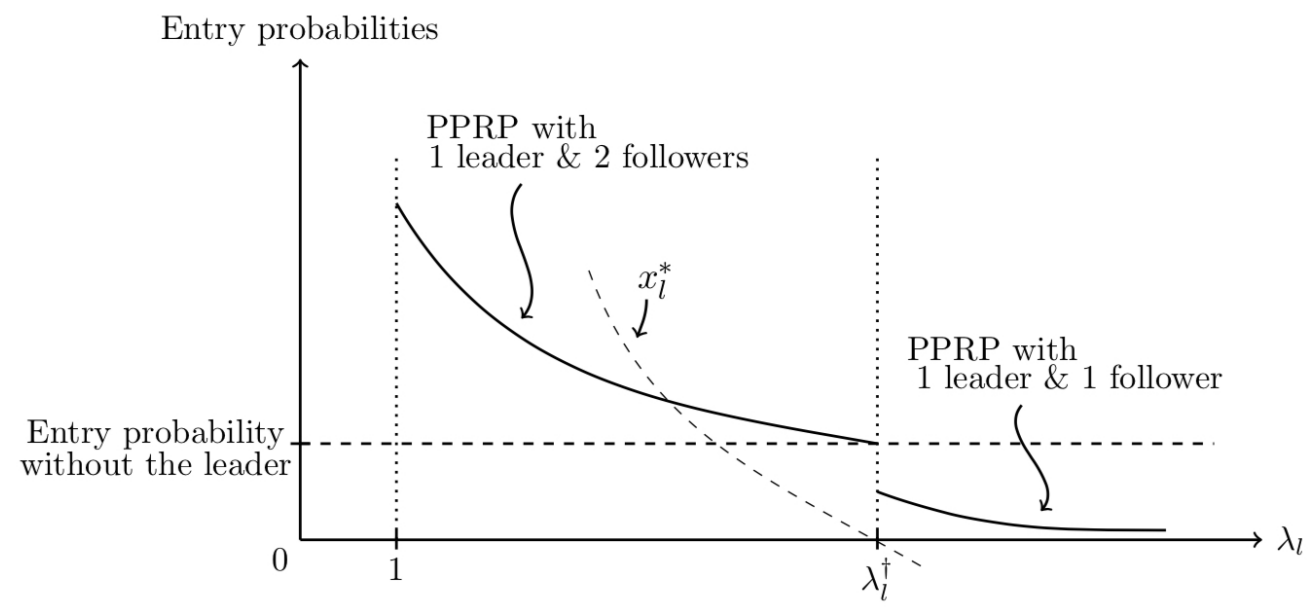

Figure 2: Comparison between two entry probabilities with or without excluding the leader in the auction

\section{Concluding remarks}

We study the model of single-license auctions with heterogeneous incumbents. We establish the monotonicity of preemptive bidding participation with regard to the entry-loss rate. We also establish the existence of equilibria with full or partial participation of entry deterrence by heterogeneous incumbents.

Considering a model with a bipartite set of a single leader and multiple followers (in Cournot or Stackelberg competitions), we discuss conditions for equilibrium existence and policy implications. Depending on certain conditions, limiting the leader's participation can diminish or improve market efficiency and competitiveness. This suggests a general lesson for set-aside policies as well as other competition policies limiting leading incumbents: assessment of these policies depend crucially on the structure of the market and incumbent heterogeneity.

The existence of equilibria with randomized preemption is not guaranteed when the bounded heterogenity condition does not hold, as shown by counterexamples. Nevertheless, we leave it for future investigation to characterize all randomized preemption equilibria with or without the condition we provide here.

\section{Appendix: Proofs}

Proof. [Proof of Lemma 1] Let $i \in I \backslash H$ and $b_{i} \geq w_{e}$. Then $v_{i}+\Delta \pi_{i} \leq w_{e} \leq b_{i}$. Equivalently, $w_{i}-\pi_{i}(n+1) \leq w_{e} \leq b_{i}$. In what follows, we show that for all $b_{-i}$ and all $b_{i}^{\prime} \leq w_{e}, u_{i}\left(b_{i}, b_{-i}\right) \leq$ 
$u_{i}\left(b_{i}^{\prime}, b_{-i}\right)$.

Case 1. Consider $b_{-i}$ such that there is an incumbent other than $i$ who bids at least $w_{e}$, that is, $\max \left\{b_{j}: j \neq i\right\} \geq w_{e}$. Suppose $b_{i} \geq \max \left\{b_{j}: j \neq i\right\}$. If $i$ wins, then $u_{i}\left(b_{i}, b_{-i}\right)=w_{i}-$ $\max \left\{b_{j}: j \neq i\right\} \leq w_{i}-w_{e}$; otherwise, $u_{i}\left(b_{i}, b_{-i}\right)=\pi_{i}(n)$. If $i$ bids $b_{i}^{\prime}<w_{e}$, then, since another incumbent deters the entry given $b_{-i}$, $i$ 's payoff is $\pi_{i}(n)$. Since $w_{i}-w_{e} \leq \pi_{i}(n+1) \leq \pi_{i}(n)$ (the first inequality holds for $i \in I \backslash H)$ and $i$ has a positive chance of winning given $\left(b_{i}, b_{-i}\right)$, the payoff from bidding $b_{i}^{\prime}, \pi_{i}(n)$, is greater than or equal to the payoff from bidding $b_{i}$, which is a "strict mixture" of $w_{i}-\max \left\{b_{j}: j \neq i\right\}\left(\leq w_{i}-w_{e}\right)$ and $\pi_{i}(n)$. Suppose $b_{i}<\max \left\{b_{j}: j \neq i\right\}$. Then, $i$ 's payoff is $\pi_{i}(n)$, which is the same as bidding $b_{i}^{\prime}<w_{e}$.

Case 2. Consider $b_{-i}$ such that all other incumbents bid less than $w_{e}$, that is, $\max \left\{b_{j}: j \neq i\right\}<$ $w_{e}$. Then, $u_{i}\left(b_{i}, b_{-i}\right)=w_{i}-w_{e}$. If $i$ bids $b_{i}^{\prime}<w_{e}$, an entrant will win the license, and $u_{i}\left(b_{i}^{\prime}, b_{-i}\right)=$ $\pi_{i}(n+1)$. Since $i \in I \backslash H, w_{i}-w_{e} \leq \pi_{i}(n+1)$, so bidding $b_{i}^{\prime}$ yields a payoff that is greater than or equal to the payoff from bidding $b_{i}$.

Proof. [Proof of Proposition 1] We first show that each $b \in \mathbb{R}_{+}^{n} \backslash \cup_{i \in H} B^{i}$ is not an equilibrium. By Lemma 1, for $i \in I \backslash H$, bidding $b_{i} \geq w_{e}$ is weakly dominated. Let each $i \in H$ bid $b_{i}<w_{e}$. Then for $j \in H, u_{j}\left(b_{j}, b_{-j}\right)=\pi_{j}(n+1)$, but by bidding $b_{j}^{\prime} \geq w_{e}, u_{j}\left(b_{j}^{\prime}, b_{-j}\right)=w_{j}-w_{e}$. Since $w_{e}<v_{j}+\Delta \pi_{j}, u_{j}\left(b_{j}^{\prime}, b_{-j}\right)>u_{j}\left(b_{j}, b_{-j}\right)$. Let $i, j \in H$ bid $b_{i} \geq w_{e}$ and $b_{j} \geq w_{e}$, respectively. Then $u_{i}\left(b_{i}, b_{-i}\right) \leq w_{i}-w_{e}$, but by bidding $b_{i}^{\prime}<w_{e}, u_{i}\left(b_{i}^{\prime}, b_{-i}\right)=\pi_{i}(n)$. Since $w_{e}>\max _{i \in I} v_{i}$, $u_{i}\left(b_{i}^{\prime}, b_{-i}\right)>u_{i}\left(b_{i}, b_{-i}\right)$. Next, we show that for all $i \in H$, each $b \in B^{i}$ is a pure strategy Nash equilibrium. Let $i \in H$ and $b \in B_{i}$. Then $u_{i}\left(b_{i}, b_{-i}\right)=w_{i}-w_{e}>\pi_{i}(n+1)=u_{i}\left(b_{i}^{\prime}, b_{-i}\right)$ for any $b_{i}^{\prime}<w_{e}$ since $w_{e}<v_{i}+\Delta \pi_{i}$, and $u_{i}\left(b_{i}, b_{-i}\right)=w_{i}-w_{e}=u_{i}\left(b_{i}^{\prime}, b_{-i}\right)$ for any $b_{i}^{\prime} \geq w_{e}$ with $b_{i}^{\prime} \neq b_{i}$. Let $j \neq i$. Then $u_{j}\left(b_{j}, b_{-j}\right)=\pi_{j}(n)>w_{j}-w_{e} \geq u_{j}\left(b_{j}^{\prime}, b_{-j}\right)$ for any $b_{j}^{\prime} \geq b_{i}$ since $w_{e}>\max _{i \in I} v_{i}$, and $u_{j}\left(b_{j}, b_{-j}\right)=\pi_{j}(n)=u_{j}\left(b_{j}^{\prime}, b_{-j}\right)$ for any $b_{j}^{\prime}<b_{i}$.

Proof. [Proof of Lemma 2] Suppose by contradiction that $\operatorname{Pr}^{\sigma_{i}}\left[b_{i}>w_{e}\right]>0$. Then, either (i) for some $h \in H, \operatorname{Pr}^{\sigma}\left[b_{h}>\max _{j \in H \backslash\{h\}} b_{j} \geq w_{e}\right]>0$, or (ii) there is $\hat{b}>w_{e}$ such that for each $i \in H$ participating in preemption, $\operatorname{Pr}^{\sigma_{i}}\left[b_{i}=\hat{b}\right]+\operatorname{Pr}^{\sigma_{i}}\left[b_{i}<w_{e}\right]=1$ (that is, each participating incumbent in $H$ chooses the same deterring bid $\hat{b}$ above $w_{e}$ or a losing bid below $w_{e}$ ).

Case 1. For some $h \in H, \operatorname{Pr}^{\sigma}\left[b_{h}>\max _{j \in H \backslash\{h\}} b_{j} \geq w_{e}\right]>0$. Let $\sigma_{h}^{\prime}$ be a mixed strategy that is obtained by lowering all bids higher than $w_{e}$ given $\sigma_{h}$ to $w_{e}$, i.e., $\operatorname{Pr} \sigma_{h}^{\prime}\left[b_{h}=w_{e}\right]=\operatorname{Pr}^{\sigma_{h}}\left[b_{h} \geq w_{e}\right]$ and for all $b_{h}^{\prime}<w_{e}, \operatorname{Pr}_{h}^{\sigma_{h}^{\prime}}\left[b_{h} \leq b_{h}^{\prime}\right]=\operatorname{Pr}^{\sigma_{h}}\left[b_{h} \leq b_{h}^{\prime}\right]$. Let $B^{*} \equiv\left\{b: b_{h}>\max _{j \in H \backslash\{h\}} b_{j} \geq w_{e}\right\}$. For each $b \in B^{*}$, by switching from $\sigma_{h}$ to $\sigma_{h}^{\prime}$, $h$ 's payoff strictly increases from $u_{h}(b) \leq w_{h}-w_{e}$ to $\pi_{h}(n)$ or $\alpha\left(w_{h}-w_{e}\right)+(1-\alpha) \pi_{h}(n)$ for some $\alpha=\frac{1}{2}, \frac{1}{3}, \ldots, \frac{1}{n-1}$. For each $b \in B \backslash B^{*}$, by switching from $\sigma_{h}$ to $\sigma_{h}^{\prime}$, h's payoff either increases or remains the same. Since $\operatorname{Pr}^{\sigma}\left[B^{*}\right]>0$, $h$ 's expected payoff from $\sigma_{h}^{\prime}$ is greater than $h$ 's expected payoff from $\sigma_{h}$, contradicting $\sigma$ being a Nash equilibrium.

Case 2. There is $\hat{b}>w_{e}$ such that for each $i \in H$ participating in preemption, $\operatorname{Pr}^{\sigma_{i}}\left[b_{i}=\right.$ $\hat{b}]+\operatorname{Pr}^{\sigma_{i}}\left[b_{i}<w_{e}\right]=1$. Pick any $h \in H$ with $\operatorname{Pr}^{\sigma_{h}}\left[b_{h}=\hat{b}\right]>0$. Define $\sigma_{h}^{\prime}$ as in Case 1. Let $\hat{B} \equiv\left\{b: b_{h}=\hat{b}=\max _{j \in H \backslash\{h\}} b_{j}\right\}$. Then, after switching from $\sigma_{h}$ to $\sigma_{h}^{\prime}$, for any $b \in \hat{B}$, $h$ 's payoff strictly increases from $\alpha\left(w_{h}-w_{e}\right)+(1-\alpha) \pi_{h}(n)$ for some $\alpha=\frac{1}{2}, \frac{1}{3}, \ldots, \frac{1}{n-1}$ to $\pi_{i}(n)$, and for all other $b \in B \backslash \hat{B}$, $h$ 's payoff either increases or remains the same. Hence, $h$ 's expected payoff from $\sigma_{h}^{\prime}$ is greater than $h$ 's expected payoff from $\sigma_{h}$, contradicting $\sigma$ being a Nash equilibrium. 
Proof. [Proof of Lemma 3] Let any pair $\sigma_{i}, \sigma_{i}^{\prime}$ be such that $\operatorname{Pr}^{\sigma_{i}}\left[b_{i}=w_{e}\right]=\operatorname{Pr}^{\sigma_{i}^{\prime}}\left[b_{i}=w_{e}\right]$ for all bidders participating in preemption. For each $S \subseteq H$, let $\operatorname{Pr}[S]$ be the probability that all incumbents in $S$ bid $w_{e}$, and all the other incumbents in $H \backslash S$ bid an amount less than $w_{e}$. That is,

$$
\operatorname{Pr}[S] \equiv \prod_{j \in S} p_{j} \times \prod_{j \in H \backslash S}\left(1-p_{j}\right) .
$$

Then, for all $i \in H$, incumbent $i$ 's expected payoff from bidding $w_{e}$ is given as

$$
U_{i}\left(w_{e} ; p_{-i}\right) \equiv \sum_{S \in H \backslash\{i\}} \operatorname{Pr}[S]\left(\frac{1}{|S|+1}\left[w_{i}-w_{e}\right]+\frac{|S|}{|S|+1} \pi_{i}(n)\right) .
$$

On the other hand, for all $i \in H$, incumbent $i$ 's expected payoff from bidding $\bar{b}_{i}<w_{e}$ is given as

$$
U_{i}\left(\bar{b}_{i} ; p_{-i}\right) \equiv \sum_{S \in H \backslash\{i\}: S \neq \phi} \operatorname{Pr}\left[b_{-i}\right] \pi_{i}(n)+\operatorname{Pr}[\phi] \pi_{i}(n+1)
$$

Since $\operatorname{Pr}^{\sigma_{h}}\left[b_{h}=w_{e}\right]=\operatorname{Pr}_{h}^{\sigma_{h}^{\prime}}\left[b_{h}=w_{e}\right]=p_{h}$, for both mixed strategies $\sigma_{h}$ and $\sigma_{h}^{\prime}$, bidder $j$ obtains the same expected payoff as

$$
\operatorname{Pr}^{\sigma_{h}}\left[b_{j}=w_{e}\right] U_{j}\left(w_{e} ; p_{-i}\right)+\operatorname{Pr}^{\sigma_{h}}\left[b_{j}<w_{e}\right] U_{j}\left(\bar{b}_{j} ; p_{-i}\right) \text { for all } j \text { and all }\left(\sigma_{j}\right)_{j \neq h} .
$$

This implies that for each $h \in H$, such $\sigma_{h}$ and $\sigma_{h}^{\prime}$ are payoff-equivalent. Hence, given $i \in H$ and $\sigma_{-i},\left(\sigma_{i}, \sigma_{-i}\right)$ is a binary preemptive Nash equilibrium if and only if $\left(\sigma_{i}^{\prime}, \sigma_{-i}\right)$ is a binary preemptive Nash equilibrium. By repeating it for all $j \neq i,\left(\sigma_{i}, \sigma_{-i}\right)$ is a binary preemptive Nash equilibrium if and only if $\left(\sigma_{i}^{\prime}, \sigma_{-i}^{\prime}\right)$ is a binary preemptive Nash equilibrium.

Proof. [Proof of Proposition 3] Part 1. $|H|=2$. We prove the existence of a unique solution of (14) which gives $\left(p_{1}^{*}, p_{2}^{*}\right)>>0$. Note that (14) is composed of two equations below:

$$
\Phi\left(x_{-1}\right)=\lambda_{1} \Leftrightarrow \frac{1}{2} x_{2}+1=\lambda_{1} ; \Phi\left(x_{-2}\right)=\lambda_{2} \Leftrightarrow \frac{1}{2} x_{1}+1=\lambda_{2} .
$$

The unique solution is given by $x_{1}^{*}=2\left(\lambda_{2}-1\right)$ and $x_{2}^{*}=2\left(\lambda_{1}-1\right)$. Since $\left(\lambda_{1}, \lambda_{2}\right)>>(1,1)$, $\left(x_{1}^{*}, x_{2}^{*}\right)>>0$, which provides the unique FPRP equilibrium.

Part 2. $|H| \geq 3$. Let $H \equiv\{1, \ldots,|H|\}$. Assume that all incumbents in $H$ have identical entry-loss rate $\lambda_{0}$. If there is an FPRP $\left(x_{h}\right)_{h \in H}$, then by Proposition 2 and (14), there is $x_{0}^{*}$ such that $x_{0}^{*}=x_{h}$ for all $h \in H$ and $x_{0}^{*}$ is a solution of ,

$$
\Phi \underbrace{\left(x_{0}, \ldots, x_{0}\right)}_{|H|-1 \text { times }}=\lambda_{0}
$$

Note that $\Phi\left(x_{0}, \ldots, x_{0}\right)-\lambda_{0}$ takes a negative value at $x_{0}=0$, and it is continuous, strictly increasing and unbounded above. Hence, there exists a unique $x_{0}^{*}>0$ such that $\Phi\left(x_{0}^{*}, \ldots, x_{0}^{*}\right)=\lambda_{0}$. Let 
$x^{*} \equiv\left(x_{0}^{*}, \ldots, x_{0}^{*}\right)$ and $\lambda^{*} \equiv\left(\lambda_{0}, \ldots, \lambda_{0}\right)$.For each $i \in H$, each $\lambda \equiv\left(\lambda_{i}\right)_{i \in H}$, and $x \equiv\left(x_{i}\right)_{i \in H}$, let $F_{i}(\lambda, x) \equiv \Phi\left(x_{-i}\right)-\lambda_{i}$ and $F(\lambda, x) \equiv\left(F_{i}(\lambda, x)\right)_{i \in H}$. Note that

$$
D_{x} F(\lambda, x)=\left[\begin{array}{cccc}
0 & \frac{\partial \Phi\left(x_{-1}\right)}{\partial x_{2}} & \ldots & \frac{\partial \Phi\left(x_{-1}\right)}{\partial x_{|H|}} \\
\frac{\partial \Phi\left(x_{-2}\right)}{\partial x_{1}} & 0 & \cdots & \frac{\partial \Phi\left(x_{-2}\right)}{\partial x_{|H|}} \\
\vdots & \vdots & \ddots & \vdots \\
\frac{\partial \Phi\left(x_{-|H|}\right)}{\partial x_{1}} & \frac{\partial \Phi\left(x_{-|H|}\right)}{\partial x_{2}} & \cdots & 0
\end{array}\right],
$$

and for all $i, j \in H, \partial \Phi\left(x_{-i}^{*}\right) / \partial x_{i}=\partial \Phi\left(x_{-j}^{*}\right) / \partial x_{j}=c$. Then

$$
D_{x} F\left(\lambda^{*}, x^{*}\right)=c\left[\begin{array}{cccc}
0 & 1 & \cdots & 1 \\
1 & 0 & \cdots & 1 \\
\vdots & \vdots & \ddots & \vdots \\
1 & 1 & \cdots & 0
\end{array}\right] .
$$

Then using (25) and applying Implicit Function Theorem for $F(\lambda, x)$ at $\left(\lambda^{*}, x^{*}\right)$, there is an open set $U \subseteq \mathbb{R}_{+}^{H}$ containing $\lambda^{*} \in U$ and a unique continuously differentiable function $g: U \rightarrow \mathbb{R}_{+}^{H}$ such that for all $\lambda \in U, F(\lambda, g(\lambda))=0$.

Proof. [Proof of Proposition 4] Part 1. Assume $|S|=2$ and $\max _{i \in H} \lambda_{i} \in S$. Let $h \in \arg \max _{i \in H} \lambda_{i}$ and $S \equiv\{h, g\}$. From the proof of Proposition 3 , there exist strictly mixed strategies $\left(x_{h}^{*}, x_{g}^{*}\right)$ of two incumbents in $S$ such that

$$
\frac{1}{2} x_{h}^{*}+1=\lambda_{g}, \text { and } \frac{1}{2} x_{g}^{*}+1=\lambda_{h} .
$$

For all $i \in H \backslash S$, let $x_{i}^{*} \equiv 0$. It is optimal for $i$ to choose a non-deterring bid with probability 1 $\left(x_{i}^{*}=0\right)$ if (13) holds. Note that

$$
\begin{aligned}
\Phi\left(x_{-i}^{*}\right)-\lambda_{i} & =\frac{1}{3} x_{h}^{*} x_{g}^{*}+\frac{1}{2} x_{h}^{*}+\frac{1}{2} x_{g}^{*}+1-\lambda_{i} \\
& =\frac{1}{3} x_{h}^{*} x_{g}^{*}+\frac{1}{2} x_{h}^{*}+\lambda_{h}-\lambda_{i},
\end{aligned}
$$

where the second equality follows from (26). Since $\lambda_{h}-\lambda_{i} \geq 0$, we have $\Phi\left(x_{-i}^{*}\right)-\lambda_{i}>0$. Hence $\mathrm{s}(13)$ holds. The uniqueness part follows from the uniqueness of the solution for (26).

Part 2. Let $S \subseteq H$. Suppose that all incumbents in $S$ have an identical entry-loss rate $\lambda_{0}$. Consider $\lambda^{*}$ such that for all $i \in S, \lambda_{i}^{*}=\lambda_{0}$ and for all $j \in H \backslash S, \lambda_{j}^{*} \leq \lambda_{0}$.

A profile of binary preemptive mixed strategies $p^{*}$ is a symmetric PPRP equilibrium with the set of participating incumbents $S$ if (i) for all $i \in H \backslash S, p_{i}^{*}=0$, (ii) there is $p_{0}^{*}>0$ such that for all $i \in S, p_{i}^{*}=p_{0}^{*}$ and $x_{i}^{*} \equiv p_{0}^{*} /\left(1-p_{0}^{*}\right)$ and (iii) $p^{*}$ satisfies both (13) and (14).

Note that when all incumbents in $S$ choose identical $p_{0}$ and $x_{0}=p_{0} /\left(1-p_{0}\right),(14)$ can be rewritten as follows:

$$
\sum_{k=0}^{|S|-1} \frac{1}{k+1}\left(\begin{array}{c}
|S|-1 \\
k
\end{array}\right) x_{0}^{k}=\lambda_{0} .
$$


Existence of $x_{0}^{*}$ satisfying (27) is straightforward. Let $p_{0}^{*}$ be given by $x_{0}^{*}=p_{0}^{*} /\left(1-p_{0}^{*}\right)$. For all $i \in S$, let $x_{h}^{*} \equiv x_{0}^{*}$ and $p_{i}^{*} \equiv p_{0}^{*}$ and for all $i \in H \backslash S$, let $x_{i}^{*} \equiv 0$ and $p_{i}^{*} \equiv 0$. Then $p^{*}$ satisfies (14). We show that $p^{*}$ is a symmetric PPRP equilibrium with the group of participating incumbents $S$. We have only to show that $p^{*}$ satisfies (13), which establishes that it is optimal for the incumbents in $H \backslash S$ to choose non-deterring bids. Let $i \in H \backslash S$. Since $x_{i}^{*}=0$,

$$
\begin{aligned}
\Phi\left(x_{-i}^{*}\right)-\lambda_{i}= & \sum_{k=0}^{|S|} \frac{1}{k+1}\left(\begin{array}{c}
|S| \\
k
\end{array}\right) x_{0}^{* k}-\lambda_{i}^{*} \\
= & \sum_{k=0}^{|S|} \frac{1}{k+1}\left(\begin{array}{c}
|S| \\
k
\end{array}\right) x_{0}^{* k}-\sum_{k=0}^{|S|-1} \frac{1}{k+1}\left(\begin{array}{c}
|S|-1 \\
k
\end{array}\right) x_{0}^{* k} \\
& +\sum_{k=0}^{|S|-1} \frac{1}{k+1}\left(\begin{array}{c}
|S|-1 \\
k
\end{array}\right) x_{0}^{* k}-\lambda_{i}^{*} \\
= & {\left[\sum_{k=0}^{|S|} \frac{1}{k+1}\left(\begin{array}{c}
|S| \\
k
\end{array}\right) x_{0}^{* k}-\sum_{k=0}^{|S|-1} \frac{1}{k+1}\left(\begin{array}{c}
|S|-1 \\
k
\end{array}\right) x_{0}^{* k}\right]+\lambda_{0}-\lambda_{i}^{*}, }
\end{aligned}
$$

where the third equality follows from (27). Since the difference inside of the bracket is positive and and by assumption $\lambda_{0}-\lambda_{i}^{*} \geq 0$, we have $\Phi\left(x_{-i}^{*}\right)-\lambda_{i}^{*}>0$, which shows (13).

Finally using the symmetric PPRP equilibrium and applying Implicit Function Theorem as in the proof of Proposition 3, we prove the rest of the proposition. For all $x_{S} \in \mathbb{R}_{+}^{S}$, all $\lambda_{S} \in \mathbb{R}_{+}^{S}$, and all $i \in S$, let $F_{i}\left(\lambda_{S}, x_{S}\right) \equiv \Phi\left(x_{S \backslash\{i\}}, 0_{H \backslash S}\right)-\lambda_{i}$ and $F\left(\lambda_{S}, x_{S}\right) \equiv\left(F_{i}\left(\lambda_{S}, x_{S}\right)\right)_{i \in S}$. Using $x^{*}$ corresponding to the above symmetric PPRP equilibrium $p^{*}$ with the set of participating incumbents $S, F\left(\lambda_{S}^{*}, x_{S}^{*}\right)=0$. Now applying Implicit Function Theorem as in the proof of Proposition 3, there is an open set $U \subseteq \mathbb{R}_{+}^{S}$ containing $\lambda_{S}^{*}=\left(\lambda_{0}, \ldots, \lambda_{0}\right)$ and a unique continuously differentiable function $g: U \rightarrow \mathbb{R}_{+}^{S}$ such that for all $\lambda_{S} \in U, F\left(\lambda_{S}, g\left(\lambda_{S}\right)\right)=0$. Let $\lambda$ be such that $\lambda_{S} \in U$ and for all $i \in H \backslash S, \lambda_{i} \leq \max \left\{\lambda_{j}: j \in S\right\}$. Define a profile $\widehat{x}$ as $\widehat{x}_{S} \equiv g\left(\lambda_{S}\right)$ and for all $i \in H \backslash S, \widehat{x}_{i} \equiv 0$. Then for all $i \in S, F_{i}\left(\lambda_{S}, \widehat{x}_{S}\right)=0$, which means $\Phi\left(x_{S \backslash\{i\}}, 0_{H \backslash S}\right)-\lambda_{i}=0$. Hence (27) holds for all $i \in S$. We now show that (13) holds for all $i \in H \backslash S$. Let $i \in H \backslash S$. By assumption, there is $j \in S$ be such that $\lambda_{j} \geq \lambda_{i}$. Since $\widehat{x}_{i}=0$,

$$
\begin{aligned}
\Phi\left(\widehat{x}_{-i}\right)-\lambda_{i} & =\sum_{b_{-i} \in B_{-i}} \prod_{h \in H \backslash\{i\}: b_{h}=w_{e}} \widehat{x}_{h}\left(\frac{1}{\mu\left(b_{-i}\right)+1}\right)-\lambda_{i} \\
& =\sum_{b \in B} \prod_{h \in H: b_{h}=w_{e}} \widehat{x}_{h}\left(\frac{1}{\mu(b)+1}\right)-\lambda_{i} .
\end{aligned}
$$


Note that

$$
\begin{aligned}
\sum_{b \in B} \prod_{h \in H: b_{h}=w_{e}} \widehat{x}_{h}\left(\frac{1}{\mu(b)+1}\right) & =\sum_{b \in B: b_{j}=w_{e}} \widehat{x}_{j} \prod_{h \in H \backslash\{j\}: b_{h}=w_{e}} \widehat{x}_{h}\left(\frac{1}{\mu(b)+1}\right) \\
& +\sum_{b \in B: b_{j}=\bar{b}_{j}} \prod_{h \in H \backslash\{j\}: b_{h}=w_{e}} \widehat{x}_{h}\left(\frac{1}{\mu(b)+1}\right) \\
& =\sum_{b \in B: b_{j}=w_{e}} \widehat{x}_{j} \prod_{h \in H \backslash\{j\}: b_{h}=w_{e}} \widehat{x}_{h}\left(\frac{1}{\mu(b)+1}\right) \\
& +\sum_{b_{-j} \in B} \prod_{h \in H \backslash\{j\}: b_{h}=w_{e}} \widehat{x}_{h}\left(\frac{1}{\mu\left(b_{-j}\right)+1}\right) \\
& =\sum_{b \in B: b_{j}=w_{e}} \widehat{x}_{j} \prod_{h \in H \backslash\{j\}: b_{h}=w_{e}} \widehat{x}_{h}\left(\frac{1}{\mu(b)+1}\right) \\
& +\Phi\left(\widehat{x}_{-j}\right) .
\end{aligned}
$$

Using this, we rewrite

$$
\begin{aligned}
\Phi\left(\widehat{x}_{-i}\right)-\lambda_{i} & =\sum_{b \in B: b_{j}=w_{e}} \widehat{x}_{j} \prod_{h \in H \backslash\{j\}: b_{h}=w_{e}} \widehat{x}_{h}\left(\frac{1}{\mu(b)+1}\right) \\
& +\Phi\left(\widehat{x}_{-j}\right)-\lambda_{i} .
\end{aligned}
$$

Since $\Phi\left(\widehat{x}_{-j}\right)=\lambda_{j}, \widehat{x}_{j}>0$, and $\lambda_{j} \geq \lambda_{i}, \Phi\left(\widehat{x}_{-i}\right)-\lambda_{i}>0$.

Proof. [Proof of Corollary 2]By a binomial expansion, (17) can be rewritten as

$$
\frac{(1+x)^{(|S|-1)}-1}{x(|S|-1)}=\lambda_{0} \Leftrightarrow(1+x)^{(|S|-1)}-1-\lambda_{0} x(|S|-1)=0,
$$

where $x$ is a function of $|S| .{ }^{8}$ On the other hand, the entry probability of the PPRP is written as

$$
(1-p)^{|S|-1}=\frac{1}{(1+x)^{|S|-1}} .
$$

To consider changes in the entry probability with respect to changes in $|S|$ explicitly, denote $x(|S|)$. The derivative of $(1+x)^{|S|-1}$ with respect to $|S|$ then yields

$$
\begin{aligned}
\frac{d(1+x(|S|))^{|S|-1}}{d|S|}= & (|S|-1)(1+x(|S|))^{|S|-2} \frac{d x(|S|)}{d|S|}+\log (1+x(|S|))(1+x(|S|))^{|S|-1} \\
= & -(|S|-1)(1+x(|S|))^{|S|-2} \frac{\log (1+x(|S|))(1+x(|S|))^{|S|-1}-\lambda_{0} x(|S|)}{(|S|-1)(1+x(|S|))^{|S|-2}-\lambda_{0}(|S|-1)} \\
& +\log (1+x(|S|))(1+x(|S|))^{|S|-1} \\
= & \lambda_{0}(|S|-1)(1+x(|S|))^{|S|-2}\left[\frac{-\log (1+x(|S|))(1+x(|S|)+x(|S|)}{(|S|-1)(1+x(|S|))^{|S|-2}-\lambda_{0}(|S|-1)}\right]<0,
\end{aligned}
$$

\footnotetext{
${ }^{8}$ As in HJM, it is convenient to utilize a binomial expansion $\sum_{k=0}^{|S|-2}\left(\begin{array}{c}|S|-2 \\ k\end{array}\right) z^{k}=(1+z)^{|S|-2}$, and take integrals of both sides.
} 
where $\frac{d x(|S|)}{d|S|}$ can be derived implicitly from (28). We obtain the negative sign since $-\log (1+$ $x(|S|))(1+x(|S|)+x(|S|)$ is equal to zero for $x(|S|)=0$, and strictly decreasing for all $x(|S|) \geq 0$.

Proof. [Proof of Proposition 5] First, examine case (i): $\lambda_{f}>\lambda_{l}$. By the monotonicity result of Proposition $2, x_{l}^{*}>x_{f}^{*}$, and (18) implies that $x_{f}^{*}>0$, so $x_{l}^{*}>x_{f}^{*}>0$. It remains to show that the other incumbents optimally choose a non-deterring bid with probability 1 . The payoff of each $j \in H \backslash S$ y

$$
\begin{aligned}
& x_{l}^{*} \sum_{k=0}^{|S|-1} \frac{1}{k+2}\left(\begin{array}{c}
|S|-1 \\
k
\end{array}\right) x_{f}^{* k}+\sum_{k=0}^{|S|-1} \frac{1}{k+1}\left(\begin{array}{c}
|S|-1 \\
k
\end{array}\right) x_{f}^{* k}-\lambda_{j} \\
= & x_{l}^{*} \sum_{k=0}^{|S|-1} \frac{1}{k+2}\left(\begin{array}{c}
|S|-1 \\
k
\end{array}\right) x_{f}^{* k}+\lambda_{l}-\lambda_{j},
\end{aligned}
$$

where the the equality follows from (18). Since the first term must be positive, and $\lambda_{l}-\lambda_{j}>0$, we have $\Phi\left(x_{-j}^{*}\right)-\lambda_{j}>0$, implying that each incumbent $j \in H \backslash S$ chooses the deterring bid with zero probability.

However, for case (ii), $\lambda_{l}>\lambda_{f}$, the monotonicity result of Proposition 2 implies $x_{f}^{*}>x_{l}^{*}$, and furthermore, for a sufficiently great $\lambda_{l}$, we have a corresponding high value of $x_{f}^{*}$ from (18), which can produce a negative value of $x_{l}^{*}$ from (19). Hence, in this case, the existence of a PPRP equilibrium is not guaranteed.

Proof. [Proof of Proposition 6]

Part 1. By integrating both sides of a binomial expansion $\sum_{k=0}^{|S|-1}\left(\begin{array}{c}|S|-1 \\ k\end{array}\right) z^{k}=(1+z)^{|S|-1}$ , we obtain

$$
\sum_{k=0}^{|S|-1}\left(\begin{array}{c}
|S|-1 \\
k
\end{array}\right) \frac{1}{k+1} z^{k+1}=\frac{(1+z)^{|S|}-1}{|S|} .
$$

Hence we obtain (22) from (18). Similarly, by integrating both sides of a modification of a binomial expansion $\sum_{k=0}^{|S|-2}\left(\begin{array}{c}|S|-2 \\ k\end{array}\right) z^{k+1}=z(1+z)^{|S|-2}$, we have

$$
\begin{aligned}
\sum_{k=0}^{|S|-2}\left(\begin{array}{c}
|S|-2 \\
k
\end{array}\right) \frac{1}{k+2} z^{k+2} & =\frac{z(1+z)^{|S|-1}}{|S|-1}-\int_{0}^{z} \frac{1}{|S|-1}(1+t)^{|S|-1} d t \\
& =\frac{z(1+z)^{|S|-1}}{|S|-1}-\frac{(1+z)^{|S|}-1}{|S|(|S|-1)}
\end{aligned}
$$

The first term in the left-hand side of (19) can be rewritten as

$$
x_{l}^{*} \sum_{k=0}^{|S|-2} \frac{1}{k+2}\left(\begin{array}{c}
|S|-2 \\
k
\end{array}\right) x_{f}^{* k}=\frac{x_{l}^{*}}{x_{f}^{*}} \sum_{k=0}^{|S|-2} \frac{1}{k+2}\left(\begin{array}{c}
|S|-2 \\
k
\end{array}\right) x_{f}^{* k+1} .
$$


Hence, applying the previous binomian expansion, we get

$$
\sum_{k=0}^{|S|-2} \frac{1}{k+2}\left(\begin{array}{c}
|S|-2 \\
k
\end{array}\right) x_{f}^{* k+1}=\frac{\left(1+x_{f}^{*}\right)^{|S|-1}}{|S|-1}-\frac{\left(1+x_{f}^{*}\right)^{|S|}-1}{x_{f}^{*}|S|(|S|-1)},
$$

which leads to

$$
\begin{aligned}
\frac{x_{l}^{*}}{x_{f}^{*}} \sum_{k=0}^{|S|-2} \frac{1}{k+2}\left(\begin{array}{c}
|S|-2 \\
k
\end{array}\right) x_{f}^{* k+1} & =\frac{x_{l}^{*}}{x_{f}^{*}}\left[\frac{\left(1+x_{f}^{*}\right)^{|S|-1}}{|S|-1}-\frac{\left(1+x_{f}^{*}\right)^{|S|}-1}{x_{f}^{*}|S|(|S|-1)}\right] \\
& =x_{l}^{*}\left[\frac{\left(1+x_{f}^{*}\right)^{|S|-1}}{x_{f}^{*}(|S|-1)}-\frac{\left(1+x_{f}^{*}\right)^{|S|}-1}{\left(x_{f}^{*}\right)^{2}|S|(|S|-1)}\right] .
\end{aligned}
$$

The second term of the left-hand side of (19) can be rewritten as in the left-hand side of (22). Together, we get (23).

Using (22), (23) can be written as folllow:

$$
\begin{aligned}
& x_{l}^{*}\left[\frac{\left(1+x_{f}^{*}\right)^{|S|-1}}{x_{f}^{*}(|S|-1)}-\frac{\left(1+x_{f}^{*}\right)^{|S|}-1}{\left(x_{f}^{*}\right)^{2}|S|(|S|-1)}\right]+\frac{\left(1+x_{f}^{*}\right)^{(|S|-1)}-1}{x_{f}^{*}(|S|-1)}=\lambda_{f}, \\
\Leftrightarrow & \left(1+x_{l}^{*}\right)\left(1+x_{f}^{*}\right)^{|S|-1}-\frac{x_{l}^{*}\left[\left(1+x_{f}^{*}\right)^{|S|}-1\right]}{x_{f}^{*}|S|}=1+\lambda_{f} x_{f}^{*}(|S|-1), \\
\Leftrightarrow & \left(1+x_{l}^{*}\right)\left(1+x_{f}^{*}\right)^{|S|-1}-\lambda_{l} x_{l}^{*}=1+\lambda_{f} x_{f}^{*}(|S|-1),
\end{aligned}
$$

which leads to

$$
\left(1+x_{l}^{*}\right)\left(1+x_{f}^{*}\right)^{|S|-1}=\lambda_{l} x_{l}^{*}+1+\lambda_{f} x_{f}^{*}(|S|-1) .
$$

The difference in the entry probabilities of the symmetric equilibrium excluding the leader and the leader-follower equilibrium, namely the difference between (21) and (24) is given by

$$
\begin{aligned}
\left(1+x_{l}^{*}\right)\left(1+x_{f}^{*}\right)^{|S|-1}-\left(1+\hat{x}_{f}\right)^{|S|-1} & =\lambda_{l} x_{l}^{*}+\lambda_{f} x_{f}^{*}(|S|-1)-\lambda_{f} \hat{x}_{f}(|S|-1) \\
& =\lambda_{l} x_{l}^{*}+\lambda_{f}(|S|-1)\left(x_{f}^{*}-\hat{x}_{f}\right) .
\end{aligned}
$$

Therefore, $\lambda_{l} x_{l}^{*}+\lambda_{f}(|S|-1)\left(x_{f}^{*}-\hat{x}_{f}\right)<0$ (or $>0$ ) implies that exclusion of the leader increases (or decreases, respectively) the entry probability.

Part 2. If a leader-follower PPRP equilibrium with the set $S$ does not exists, there exists a leader-follower PPRP equilibrium with a subset of $S$. At least one PPRP with the leader exists with one follower by Proposition 4 (i). Fix $\lambda_{f}$. Then, for any PPRP with a subset $\widehat{S}$ of $S$, there exists a correspoding $\lambda_{l}$ value such that the entry probability from limiting the leader is higher than the PPRP if the leader's probability $x_{l}^{*}$ is equal to zero. In this case, from (19) or (23), each follower's $x_{f}^{*}$ is identical to that of a symmetric equilibrium case with $\widehat{S}$. From Corollary 2, we know that the entry probability from limiting the leader is higher than this PPRP with $x_{l}^{*}=0$.

A PPRP equilibrium $\left(x_{l}^{*}, x_{f}^{*}\right)$ is a solution of simultaneous equations with (22) and (23). Consider a Jacobian matrix from the simultaneous equations such that 


$$
\left[\begin{array}{cc}
0 & \frac{\partial\left[\frac{\left(1+x_{f}^{*}|S|-1\right.}{x_{f}^{*}|S|}\right]}{\partial x_{f}} \\
\frac{\left(1+x_{f}^{*}\right)^{|S|-1}}{x_{f}^{*}(|S|-1)}-\frac{\left(1+x_{f}^{*}|S|-1\right.}{\left(x_{f}^{*}\right)^{2}|S|(|S|-1)} & \partial\left\{x_{l}^{*}\left[\frac{\left(1+x_{f}^{*}|S|-1\right.}{x_{f}^{*}(|S|-1)}-\frac{\left.\left.\frac{\left(1+x_{f}^{*}\right)^{(S \mid}-1}{\left(x_{f}^{*}\right)^{2}|S|(|S|-1)}\right]+\frac{\left(1+x_{f}^{*}(|S|-1)\right.}{x_{f}^{*}(|S|-1)}\right\}}{\partial x_{f}}\right\}\right.
\end{array}\right]
$$

where

$$
\frac{\partial\left[\frac{\left(1+x_{f}^{*}\right)^{|S|}-1}{x_{f}^{*}|S|}\right]}{\partial x_{f}}=\frac{\left(1+x_{f}^{*}\right)^{|S|-1} x_{f}^{*}|S|-\left[\left(1+x_{f}^{*}\right)^{|S|}-1\right]}{\left(x_{f}^{*}\right)^{2}}>0,
$$

since the numerator is zero if $x_{f}^{*}=0$ and its derivative $(|S|-1)\left(1+x_{f}^{*}\right)^{|S|-2} x_{f}^{*}|S|$ is positive for all $x_{f}^{*} \geq 0$. On the other hand, $\frac{\left(1+x_{f}^{*}\right)^{|S|-1}}{x_{f}^{*}(|S|-1)}-\frac{\left(1+x_{f}^{*}\right)^{|S|}-1}{\left(x_{f}^{*}\right)^{2}|S|(|S|-1)}>0$ for $x_{f}^{*} \geq 0$ because it is from the first term (19). Thus, the determinant of the matrix is negative. By Implicit Function Theorem, this dominance still holds for other PPRP equilibria with a neighborhood of $\lambda_{l}$ due to continuity.

\section{References}

Amaldoss, W. and Sanjay, J. (2002), David vs. Goliath: An Analysis of Asymmetric Mixed-Strategy Games and Experimental Evidence, Management Science, 48, 972-991.

Ayres, I. and Cramton, P. (1996), Deficit Reduction Through Diversity: How Affirmative Action at the FCC Increased Auction Competition, Stanford Law Review, 48, 761-815.

Athey, S., Coey, D. and Levin, J. (2013), Set-Asides and Subsidies in Auctions, American Economic Journal: Microeconomics, 5, 1-27.

Arrow, K. (1962), Economic welfare and the allocation of resources for inventions, in R. Nelson, ed., The Rate and Direction of Inventive Activity, Princeton University Press. Institute of Development Studies Bulletin, University of Sussex 27, 6-1

Bernheim, B. (1984), Strategic deterrence of sequential entry into an industry, Rand Journal of Economics, $15,1-11$.

Choi, J.P. and Gerlach, H. (2018), Optimal Cross-Licensing Arrangement: Collusion versus Entry Deterrence, working paper.

Crawford, V.P. and Smallwood, D.E. (1984), Comparative Statics of Mixed-Strategy Equilibria in Noncooperative Two-Person Games, Theory and Decision, 16, 225-232.

Cheng, L. and Zhu, M. (1995), Mixed-strategy Nash equilibrium Based upon Expected Utility and Quadratic Utility, Games and Economic Behavior, 9, 139-150.

Gilbert, R.J. and Newbery, D. (1982), Preemptive patenting and the persistence of monopoly, American Economic Review, 72, 514-526.

Gilbert, R.J. and Vives, X. (1986), Entry deterrence and the free-rider problem, Review of Economic Studies, 53, 71-83. 
Hoppe, H.C., Jehiel, P. and Moldovanu, B. (2006), License Auctions and Market Structure, Journal of Economics \& Management Strategy, 15, 371-396.

Jehiel, P. and Lamy, L. (2015), On Discrimination in Auctions with Endogenous Entry, American Economic Review, 105, 2595-2643.

Jehiel, P. and Moldovanu, B. (2000), Auction with Downstream Interaction among Buyers, Rand Journal of Economics, 31, 768-791.

Jehiel, P. and Moldovanu, B. (2001), Efficient Design with Interdependent Valuations, Econometrica, 69, $1237-1259$.

Kirkegaard, R. (2012), A Mechanism Design Approach to Ranking Asymmetric Auctions , Econometrica, 80, 2349-2364.

Lebrun, B. (1999), First price auctions in the asymmetric N bidder case, International Economic Review, 40, 125-142.

Maskin, E. and Riley, J. (2000), Asymmetric Auctions, Review of Economic Studies, 67, 413-438.

Sharkey, W.W. and Sibley, D.S. (1993), A Bertrand model of pricing and entry, Economics Letters, 41, 199-206.

Waldman, M. (1987), Noncooperative entry deterrence, uncertainty, and the free-rider problem, Review of Economic Studies, 54, 301-310. 